\title{
Cardiorespiratory Coupling in Health and Disease
}

\author{
Alfredo J. Garcia III ${ }^{1}$, Jenna E. Koschnitzky ${ }^{1}$, Tatiana Dashevskiy ${ }^{1}$, and Jan-Marino \\ Ramirez ${ }^{1,2}$ \\ ${ }^{1}$ Center for Integrative Brain Research, Seattle Children's Research Institute, University of \\ Washington, Seattle, WA 98101, USA \\ ${ }^{2}$ Department of Neurological Surgery, University of Washington, Seattle, WA 98101, USA
}

\begin{abstract}
Cardiac and respiratory activities are intricately linked both functionally as well as anatomically through highly overlapping brainstem networks controlling these autonomic physiologies that are essential for survival. Cardiorespiratory coupling (CRC) has many potential benefits creating synergies that promote healthy physiology. However, when such coupling deteriorates autonomic dysautonomia may ensue. Unfortunately there is still an incomplete mechanistic understanding of both normal and pathophysiological interactions that respectively give rise to CRC and cardiorespiratory dysautonomia. Moreover, there is also a need for better quantitative methods to assess CRC. This review addresses the current understanding of CRC by discussing: (1) the neurobiological basis of respiratory sinus arrhythmia (RSA); (2) various disease states involving cardiorespiratory dysautonomia; and (3) methodologies measuring heart rate variability and RSA.
\end{abstract}

\section{Keywords}

cardiorespiratory coupling; respiratory sinus arrhythmia; parasympathetic; nucleus ambiguus; preBötzinger complex; Rett Syndrome; Sudden Infant Death Syndrome; Apneas of prematurity; sleep disordered breathing

\section{Introduction}

The neuronal control of breathing and heart rate (HR) are closely linked, functionally as well as anatomically. Cardiorespiratory coupling (CRC) is perhaps best typified by the occurrence of respiratory sinus arrhythmia (RSA). As early as 1936, Anrep, Pascual and Rössler proposed that the heart rate sinus arrhythmia is caused by the regulation of cardiac vagal outflow involving the same neuronal processes that generate the respiratory rhythm and reside within the brainstem (Anrep et al., 1936). Indeed, extensive overlap has been confirmed between brainstem areas that control breathing and those that control cardiovascular functions. In addition to a potential role of the pons in controlling CRC (Dick et al., 2009), there are well defined medullary interactions including those between the so called pre-Bötzinger complex (preBötC) and the cardiac vagal neurons located within the nucleus ambiguus (NA) (Spyer and Gilbey, 1988; Mendelowitz, 1996; Dergacheva et al., 2010). The close interaction between cardiac and respiratory control synergizes these autonomic functions that are critical for survival. This coupling is not only important for the

\footnotetext{
(C) 2012 Elsevier B.V. All rights reserved.
}

Publisher's Disclaimer: This is a PDF file of an unedited manuscript that has been accepted for publication. As a service to our customers we are providing this early version of the manuscript. The manuscript will undergo copyediting, typesetting, and review of the resulting proof before it is published in its final citable form. Please note that during the production process errors may be discovered which could affect the content, and all legal disclaimers that apply to the journal pertain. 
homeostatic regulation of blood gases, but a tight coupling of cardiorespiratory control is also critical for regulating central nervous functions, such as arousal. There is increased evidence that cortical and brainstem arousal is linked to the generation of the sigh, an augmented breath which is associated with a characteristic biphasic HR change. The magnitude of the sigh-linked HR change is predictive for the degree and type of arousal (Thach and Lijowska, 1996; Thach, 2002). However, the mechanisms that link the sigh, heart rate change and the arousal remain unknown. Thus, it is currently also unclear why a larger heart rate change is associated with a decreased arousal threshold. Altered cardiovascular function is commonly associated with respiratory diseases and dysautonomias (Trang et al., 2003; Lin et al., 2004; Weese-Mayer et al., 2008b; Cazzola et al., 2012). Respiratory dysfunction can negatively impact cardiovascular health and vice versa. However, at the same time there are potential benefits associated with proper CRC (Hayano et al., 1996; Ben-Tal et al., 2012). In this review we will discuss the importance and basis of CRC in health and disease. The review centers around three specific aspects: (1) the neurobiological basis of CRC and particularly, respiratory sinus arrhythmia (RSA); (2) dysautonomia states associated with the decline of CRC and function; and (3) computational approaches examining heart rate variability (HRV).

\section{The Neurobiological Basis of RSA}

RSA occurs during both normal breathing (i.e., eupnea) and augmented breathing patterns (i.e., sighs). It is characterized by a heart rate (HR) increase during inspiration and a HR decrease during expiration. RSA is believed to represent a healthy form of HRV and is hypothesized to improve energetic efficiency of gas exchange (Hayano et al., 1996) or alternatively, to assist in reducing cardiac work while maintaining healthy blood gas levels (Ben-Tal et al., 2012). Sighs and concomitant RSA commonly occur at the onset of arousal and are hypothesized to contribute to the mechanistic process of recovering airway patency following occlusion (Remmers et al., 1978; Roberts et al., 1986; Wulbrand et al., 2008). RSA is normally measured and assessed in young healthy individuals as high frequency heart rate variability (HRV). Both sympathetic and parasympathetic activities are responsible for the generation of RSA.

Sympathetic activity depends on the activity of presympathetic neurons that originate in the rostral ventrolateral medulla and that are modulated by respiratory activity (Pilowsky, 1995; Zoccal et al., 2008; Costa-Silva et al., 2010; Moraes et al., 2012). Coupling of the sympathetic nervous system to respiratory activity is readily observed in splanchnic, cardiac, renal and adrenal nerves all exhibiting peak activity during phrenic nerve discharge (Numao et al. 1987). Specifically, this pattern of sympathetic activity ramps up during inspiration and reaches a peak during late-inspiration and the beginning of post-inspiratory activity (Miyawaki et al., 1996; Zoccal et al., 2008; Costa-Silva et al., 2010).

In addition to these sympathetic interactions, baseline HR changes can also be attributed to the cardioinhibitory influence by the parasympathetic nervous system (Kunze, 1972; Pickering et al., 1972; Stornetta et al., 1987; Dergacheva et al., 2010), which as will be discussed in the subsequent sections depends on the interactions between the preBötC and the NA. The balance between sympathetic and parasympathetic control is dependent on the developmental and behavioral state of the organism.

RSA is already observed prenatally at a time when lungs still do not participate in gas exchange. Fetal RSA has been recorded at gestational week 36 (Groome et al., 1994b; Groome et al., 1994a; Gustafson et al., 2011) and it is likely one of the first signs of autonomic CRC. At this time, parasympathetic activity appears to dominate CRC as heart rate decreases and high frequency HRV increases during episodes of fetal breathing 
(Gustafson et al., 2012). After parturition, the autonomic nervous system continues to mature at which point the sympathetic system will also contribute to changes in HRV, which is most obvious during the regulation of the sleep wake cycle. It has been suggested that an increased sympathetic tone contributes to the known decreased high frequency HRV during wakefulness, while a decreased sympathetic activity during slow wave sleep (Van de Borne et al., 1994) may lead to an increased HRV (Harper et al., 1978; Trelease et al., 1981). The postnatal increase in sympathetic tone may in part be due to the development of oxygen sensitivity in the carotid bodies (Carroll et al., 1993; Sovik et al., 1999; Carroll and Kim, 2005; Donnelly et al., 2009; Gauda et al., 2009) and may contribute to the gradual stabilization of cardiorespiratory activity. Thus, the strength of RSA is determined by a cardiorespiratory network involving both the peripheral and central nervous system.

While the degree of contribution of peripheral input (including both baroreceptors and chemoreceptors) to RSA is still debated (Eckberg, 2009; Karemaker, 2009a, b), lung inflation is not essential for sigh generation (Lieske et al., 2000), and its accompanying RSA (Wulbrand et al., 2008). Moreover, HR remains coupled to brainstem respiratory rhythms when subjects are artificially ventilated at different rates (Spyer and Gilbey, 1988; Daly, 1991; Shykoff et al., 1991). Thus, although peripheral receptor input may modulate the strength of RSA as postulated by Anrep et al. (1936), RSA is sufficiently coordinated within the central nervous system to function without peripheral inputs (Anrep et al., 1936).

\section{Neurobiological origins of RSA}

Several in vivo studies have demonstrated respiratory modulation of brainstem neurons involved in autonomic cardiac and cardiovascular control (Gilbey et al., 1984; Guyenet and Koshiya, 1995; Mandel and Schreihofer, 2006). Cardiac vagal motoneurons in the NA discharge during expiration, with a characteristic silence during inspiration. In cats, Gilbey et al. (1984) demonstrated that these cardiac neurons discharge primarily during the so called phase-I expiration (i.e., post-inspiration). These authors also demonstrated that the neuronal discharge followed central respiratory activity and not lung inflation. But, the neuronal control of CRC seems to be not limited to a local control of NA neurons. Neurons located more rostrally to the NA, within the rostral ventrolateral medulla (RVLM), exhibited also respiratory-related changes in their membrane potential (Lipski et al., 1996; Granata and Cohen, 2004), but these activities were more diverse. Bulbospinal and barosensitive RVLM neurons showed either peak or nadir activity during inspiration (McAllen and Blessing, 1987), and similar discharge pattern were described for the caudal ventrolateral medulla (Mandel and Schreihofer, 2006) indicating that complex interactions exist throughout the brainstem. The use of the in situ working heart-brainstem preparation suggested that input from the pons is important for the CRC (Dick et al., 2009). One possible role is that pontine-mediated excitation generates postinspiratory activity in cardiac vagal neurons (Dick et al., 2009), while the inspiratory-related inhibition of these neurons may originate within the medulla (Mendelowitz and Kunze, 1991). Yet, while the pons clearly plays a role in modulating CRC, Nucleus ambiguus neurons can also exhibit inspiratory inhibition as well as post-inspiratory activation as can be demonstrated in isolated medullary slices - i.e. in the absence of the pons (Figure 1; Garcia III, AJ and Ramirez, JM in preparation). Thus, while the final neural pathway by which vagal tone is expressed on HR resides not only within the medullary brainstem in preganglionic cardiac vagal neurons of the $\mathrm{NA}\left(\mathrm{CVN}_{\mathrm{NA}}\right)$, this medullary area seems to contain sufficient neuronal circuitry to exhibit the basic activation pattern that characterizes these neurons also under in vivo conditions as already postulated by Gilbey and colleagues (1984). 


\section{Neuromodulation of preBötzinger complex neurons and $C \mathrm{~N}_{\mathrm{NA}}$}

Critical for understanding the medullary mechanisms underlying cardiorespiratory coupling is the so called preBötC (Smith et al., 1991), a brainstem area that in vivo (Smith et al., 1991; Ramirez et al., 1998; Gray et al., 2001; Schwarzacher et al., 2011) and in isolation generates not only inspiratory, but also post-inspiratory activity (Ramirez et al., 1997b). Indeed medullary slices containing the preBötC are capable of generating three distinct activities that can be quantitatively and qualitatively discriminated; these three activities have resemblance with many aspects of eupneic, gasping and sigh activity (Lieske et al., 2000). The preBötC is essential for breathing as indicated by several studies (Ramirez et al., 1998; Gray et al., 2001; Tan et al., 2008). For example, acute lesioning of the preBötC complex in fully alert rodents leads to the immediate cessation of breathing (Tan et al., 2008). Equally convincing is the demonstration that animals fail to breathe, i.e. fail to generate inspiratory as well as expiratory activity following the genetic ablation of those neurons that give rise to the rhythmicity within the preBötC (" the so called DBX1 neurons", (Gray et al., 2010)). Of particular interest for this review are retrograde labeling studies indicating that $\mathrm{CVN}_{\mathrm{NA}}$ are anatomically positioned in the medulla in close proximity to the preBötC (Irnaten et al., 2001). This juxtaposition of $\mathrm{CVN}_{\mathrm{NA}}$ to the essential respiratory rhythm generator offers a unique opportunity to investigate the basis of neuronal CRC as both rhythmogenesis from the preBötC and coupling of $\mathrm{CVN}_{\mathrm{NA}}$ activity to the respiratory rhythm is preserved in rhythmic brainstem slices (Mendelowitz, 1996; Wang et al., 2001; Evans et al., 2005). Consequently, electrophysiological recordings from retrogradely labeled $\mathrm{CVN}_{\mathrm{NA}}$ in rhythmic brainstem slices have greatly facilitated our understanding of the dynamic interplay between respiratory rhythmogenesis, $\mathrm{CVN}_{\mathrm{NA}}$ activity and neuromodulation, interactions that are critical for the regulation of CRC and RSA at higher levels of physiological organization.

In spontaneously active rhythmic slices that contain the preBötC, $\mathrm{CVN}_{\mathrm{NA}}$ receive phasic GABAergic and glycinergic inhibition that coincides with inspiratory bursts from the hypoglossal nucleus. Under control conditions GABAergic inhibition of $\mathrm{CVN}_{\mathrm{NA}}$ actively involves $\beta_{2}$-containing nicotinic receptors but not a 7-containing nicotinic receptors (Neff et al., 2003). Moreover, noradrenergic neuromodulation of $\mathrm{CVN}_{\mathrm{NA}}$ mediated by $\mathrm{a}_{1}$ adrenergic receptors facilitate both glycinergic and GABAergic inhibition (Boychuk et al., 2011) while activation of $\beta_{2}$-adrenergic receptors suppresses inhibition of $\mathrm{CVN}_{\mathrm{NA}}$ (Bateman et al., 2012). In the preBötC, norepinephrine stabilizes rhythmogenesis stimulating both the strength and frequency of inspiratory bursts involving different receptor subtypes (Viemari and Ramirez, 2006; Viemari et al., 2011).

During a hypoxic challenge, both cardiac and respiratory activities exhibit stereotypical biphasic changes in their frequency patterns, and it has been hypothesized that sympathetic activation initially predominates, during the phase which co-insides with the augmentation of HR and respiratory rates. Subsequently, both, heart and respiratory rates enter into a period of depression, which may be related to a phase of parasympathetic dominance (Taylor and Butler, 1982; Schuen et al., 1997; Deshpande et al., 1999). Thus, it is possible that the stereotypical hypoxic response may involve a shift of balance between parasympathetic and sympathetic dominance. However, further mechanistic studies will be necessary to confirm the postulated shift in sympathetic and parasympathetic control. Mechanistic insights can potentially be gained in in vitro studies, because the neuronal elements critical for respiratory rhythmogenesis and parasympathetic control are not only retained in rhythmic medullary brainstem slices, but both control systems also exhibit stereotypical biphasic hypoxic responses (Ramirez et al., 1997a; Telgkamp and Ramirez, 1999; Thoby-Brisson and Ramirez, 2000; Neff et al., 2004; Evans et al., 2005; Pena and Ramirez, 2005; Hill et al., 2011). Intracellular recordings from $\mathrm{CVN}_{\mathrm{NA}}$ show that both GABAergic and glycinergic inhibition to $\mathrm{CVN}_{\mathrm{NA}}$ is initially augmented, and subsequently 
depressed during the hypoxic response (Neff et al., 2004). A depression of synaptic inhibition has also been demonstrated for respiratory neurons both in vitro (Wilken et al., 1998) and in vivo (Schmidt et al., 1995). Thus, at the level of the networks isolated in the brainstem slice, hypoxia-mediated changes in the phasic inhibition are not limited to the activity of $\mathrm{CVN}_{\mathrm{NA}}$, but are also seen in the respiratory rhythm generator itself. Much has already been learned about the cellular mechanisms underlying the hypoxic response of the isolated preBötC (Ramirez et al., 1997a; Lieske et al., 2000; Thoby-Brisson and Ramirez, 2000; Pena et al., 2004; Pena and Ramirez, 2005; Hill et al., 2011). Briefly, during this hypoxic response, the preBötC undergoes a dramatic reconfiguration. Under control conditions, two inward conductances, $\mathrm{I}_{\mathrm{CAN}}$ and $\mathrm{I}_{\mathrm{NaP}}$, are critical for rhythm generation while inhibitory synaptic mechanisms are involved in shaping respiratory activities and establishing the different phases of breathing. Exposed to hypoxia, the respiratory network transitions into a network state in which synaptic inhibition is suppressed and rhythmogenesis becomes largely dependent on $\mathrm{I}_{\mathrm{NaP}}$ but not $\mathrm{I}_{\mathrm{CAN}}$ (Pena et al., 2004; Pena and Ramirez, 2005; Hill et al., 2011). This network reconfiguration marks the transition from eupnea into gasping (Lieske et al., 2000; Pena et al., 2004; Pena and Ramirez, 2005), but it may also contribute to the hypoxic network reconfiguration that characterizes changes in cardiorespiratory coupling in general and $\mathrm{CVN}_{\mathrm{NA}}$, in particular. Such a conclusion, also raises the possibility that peripheral chemoreceptors do not play a significant role in respiratory-parasympathetic coupling during hypoxia. However, as already discussed above, medullary mechanisms will also be complemented by changes in areas rostral to the preBötzinger complex that will include for example the pons and Bötzinger complex. In a similar fashion, peripheral chemoreceptors may also be involved in changes to respiratoryparasympathetic activities during hypoxia. Little, however, is known about this issue and thus, the precise role of peripheral input during hypoxia in the context of CRC remains an open issue.

Much is known about the role of neuromodulation. During hypoxia, serotonergic neuromodulation provides excitatory drive to both neuronal populations. In $\mathrm{CVN}_{\mathrm{NA}}$, serotonergic neuromodulation involves the activation of $5 \mathrm{HT}_{3}$ receptors (Dergacheva et al., 2009) while in the preBötC serotonergic neuromodulation of respiratory rhythmogenesis involves $5 \mathrm{HT}_{2 \mathrm{~A}}$ receptors (Pena and Ramirez, 2002; Tryba et al., 2008; Ptak et al., 2009). Moreover, noradrenerigic neuromodulation via $a_{2}$-noradrenergic receptors also converge onto a pathway involving $5 \mathrm{HT}_{2 \mathrm{~A}}$ receptors during hypoxia (Viemari et al., 2011). Following reoxygenation from hypoxia, purinergic drive increases excitability of $\mathrm{CVN}_{\mathrm{NA}}$ via a $\mathrm{P} 2 \mathrm{X}$ mechanism (Griffioen et al., 2007; Jameson et al., 2008). While not exclusively examined during re-oxygenation, purinergic neuromodulation of preBötC neurons has been shown to occur through a balance between ATP activation of P2Y1 purinoreceptors that increase burst frequency and adenosine activation of P1R that suppresses burst frequency (Zwicker et al., 2011). In conclusion, the relative proximity of $\mathrm{CVN}_{\mathrm{NA}}$ to the preBötC appears to provide one important avenue by which the neuronal substrates for cardiac and respiratory control interact and couple. This interaction is largely preserved in the rhythmic in vitro slice preparation and may represent a fundamental unit for CRC and specifically RSA at higher levels of physiological organization. Moreover, this coupling at the neuronal level appears to exist not only during well-oxygenated states but also in response to hypoxia, and it seems to involve similar but not identical mechanisms of neuromodulation.

\section{Cardiorespiratory dysautonomia}

Many disease states present with cardiorespiratory instabilities and dysautonomia. Such cardiorespiratory dysautonomias include apneas of prematurity (AoP), Sudden Infant Death Syndrome (SIDS), Obstructive Sleep Apnea (OSA), Familial Dysautonomia (FD) and Rett Syndrome. This section provides a brief overview with particular emphasis on the potential 
mechanisms associated with the alterations of CRC. These mechanisms range from developmental immaturity of cardiorespiratory physiologies, to brainstem abnormalities, to sympatho-vagal imbalance.

Many disorders such as hypertension or heart failure are characterized by diminished and unresponsive cardiac vagal activity (Vanoli et al., 1991). Thus, a diminished cardiac vagal activity is indicative of an underlying pathology and increased risk for sudden cardiac death. A diminished HRV is, for example, characteristic for partially asphyxiated and distressed newborns (Meny et al., 1994). Such pathophysiological changes in CRC become most obvious during the sigh and accompanying RSA. Children that later died of Sudden Infant Death Syndrome had a diminished heart rate change during the sigh (Kahn et al., 1988; Franco et al., 1998; Franco et al., 2003). Similarly, a sigh-related heart rate decrease has been reported in Familial Dysautonomia (Weese-Mayer et al., 2008a) - See Figure 2.

\section{Rett Syndrome}

A different form of autonomic dysautonomia has been reported in Rett Syndrome. These children show decreased HRV and a reduced RSA (Weese-Mayer et al. 2006; Guideri et al. 2001; Sekul et al. 1994; Guideri et al. 1999).

These children often exhibit also prolonged respiratory events that have been termed "breathholds" (Weese-Mayer et al., 2006). The neuronal basis of these breathholds has been extensively studied in mice with the Mecp2 mutation, and it was concluded that the inspiratory pause (apnea) is associated with an overactive expiratory effort against the closed glottis characteristic of a breathhold (Abdala et al., 2010). Yet during this time the cardiorespiratory coupling is different from a normal breathhold. While normal breathholds are associated with a HR decrease (Figure 3A), breathholds in Rett Syndrome show a characteristic biphasic HR response. An initial HR increase associated with an inspiratory effort is followed by an abrupt HR decrease associated with the over-activated postinspiratory effort. However, instead of maintaining a decreased HR, these children generate a secondary delayed HR increase which outlasts the breathhold and thus becomes uncoupled from the respiratory network (Figure 3B). The fact that the HR increase continues as breathing resumes also indicates that this heart rate change is not "simply" reflexive, such as is the case for example in the so called Valsalva maneuver, but rather that this characteristic HR response is likely generated centrally within the central nervous system. For example, a loss of the MECP2 gene in GABAergic neurons throughout the central nervous system mimics the Rett syndrome, including the respiratory phenotype (Chao et al. 2010). Thus, given the important role of inhibition to $\mathrm{CRC}$ at the level of the preBötC and $\mathrm{CVN}_{\mathrm{NA}}$, one may hypothesize that the circuitry between preBötC neurons and $\mathrm{CVN}_{\mathrm{NA}}$ is functionally disrupted in Rett Syndrome leading to the observed changes in cardiorespiratory function. Alternatively, exaggerated sympathetic activity may also give rise to the observed differences in the HR responses during breathholds in children with Rett Syndrome. However, the mechanistic basis of abnormal CRC in this disease state remains unknown.

\section{Apneas of Prematurity (AoP)}

AoP are identified as prolonged respiratory pauses (15-20sec in duration) associated with concurrent bradycardia (heart rate $<2 / 3$ of baseline for $4 \mathrm{~s}$ ) that is accompanied with arterial oxygen desaturation $\left(\mathrm{SpO}_{2}<80 \%\right.$; $>4 \mathrm{sec}$ in duration). AoP occur in infants born prior to gestational week 37 (Moriette et al., 2010). At the time of birth, even full term infants show cardiorespiratory instabilities that are indicative of an immature cardiorespiratory system (Hoppenbrouwers et al., 1977; Glotzbach et al., 1989b; Glotzbach et al., 1989a; Barrington and Finer, 1990), yet prematurely born infants possess a cardiorespiratory system that is 
even further underdeveloped. Thus, it has been hypothesized that AoP is not necessarily the result of a pathophysiological deficiency but rather the consequence of a neuronal control system that is still in an early immature stage (Chardon et al., 2004; Abu-Shaweesh and Martin, 2008; Carroll and Agarwal, 2010). Indeed, AoP directly relates to the degree of prematurity and generally resolve with time and postnatal maturation (Eichenwald et al., 1997; Ramanathan et al., 2001).

Lung immaturity and underdeveloped airway tone are well-documented events occurring with premature birth (Lemke et al., 1998; Colin et al., 2010). The immaturity of these respiratory components may perpetuate inadequate ventilation leading to a state of hypoxia if not counterbalanced by sustained carotid body activation (Cross and Oppe, 1952; Aizad et al., 1984). In AoP, peripheral chemosensory input appears significantly elevated (Haider et al., 1995; Di Fiore et al., 2001). Although the sustained increase in peripheral afferent drive may assist in maintaining near normal blood oxygen levels, it may also have detrimental consequences as it could lead to hyperventilation that drives carbon dioxide levels below the apneic threshold (Al-Matary et al., 2004). The breathing cessation in turn will eventually restore central ventilatory drive resulting in an oscillation of carbon dioxide levels around the apneic threshold which may perpetuate periodic breathing and bradycardia in AoP (AlMatary et al., 2004; Gauda et al., 2004). Thus, this possible scenario involves not only lung and airway immaturity but also implicates a role for the carotid bodies. But, immaturity of the central nervous system likely plays an additional role in the events that lead to autonomic disturbances associated with AoP.

Disturbances in autonomic control become obvious when comparing the cardio-respiratory response to hypoxia in premature and full/near term infants (Alvaro et al., 1992). As already mentioned above, the stereotypical biphasic hypoxic response is characterized by an initial augmentation in respiratory and heart rate that is followed by a secondary depression in both parameters. By contrast, small ( $\triangle 500 \mathrm{~g}$ ) preterm infants go directly into a ventilatory depression in response to hypoxia (Alvaro et al., 1992). This monophasic response observed in preterm infants is similar to the in utero response to hypoxia (Boddy et al., 1974; Alvarez et al., 1992) and is thought to represent an intermediate stage between fetal and adult responses (Alvaro et al., 1992). It has been hypothesized that pontine inhibition is responsible for depressing fetal breathing movements during hypoxia (Moore et al., 1996). Consistent with this hypothesis, central inhibitory mechanisms appear to be predominant in preterm neonates (Rigatto and Brady, 1972; Rigatto et al., 1975a, b; Bissonnette, 2000). The lack of an initial hypoxic augmentation could have detrimental consequences for infants with AoP, as even the most transient drops in blood oxygen may result in severe bradycardia and a dramatic exaggeration of hypoxic events (Alvarez et al., 1992; Gauda et al., 2004).

In line with the hypothesis that AoP is the result of a developmental immaturity, studies in premature infants that are either born closer to term or tested at later postnatal ages show the stereotypical biphasic cardiorespiratory response to hypoxia (Rigatto et al., 1975a, b; Martin et al., 1998; Verbeek et al., 2008). However, premature infants with periodic breathing exhibit an initial hypoxic ventilatory response that is increased and a depression that is blunted when compared to continuously breathing counterparts (Nock et al., 2004). Moreover, periodic breathing infants also exhibit a greater duration in hyperoxic-induced apnea (Cross and Oppe, 1952; Aizad et al., 1984; Al-Matary et al., 2004). Together these observations suggest that an exaggerated sympathetic response of the carotid bodies may exist in children with AoP. Hence, the contribution of peripheral input may contribute to the etiology of AoP in a similar fashion to the proposed differences in the central nervous system of preterm infants. Thus, the mechanistic basis of AoP may actually involve both peripheral and central components and remains to be resolved. Despite this paucity in mechanistic understanding, altered CRC is readily observed in preterm infants in the form of 
lower HRV in the high frequency range (Longin et al. 2006; Selig et al., 2011). Furthermore, the ratio of high frequency HRV (parasympathetic component) to low frequency HRV (sympathetic component) is smaller compared to term infants (Selig et al., 2011) also supporting the role of sympatho-vagal imbalance altered CRC in AoP.

In summary, AoP appear to be due to a physiological underdevelopment in cardiorespiratory control rather than a pathophysiological deficit. This underdevelopment not only includes end organs, such as the lungs and airway, but also appears to involve prematurity in both peripheral and central components responsible for autonomic control over cardiorespiratory function. Although AoP commonly self-resolve, the chronic state of increased in sympathetic activation needed to avoid hypoventilation in premature infants may be a risk factor for the future occurrence of cardiovascular disease, sleep apneas, and other cardiorespiratory disorders (Rosen et al., 2003; Montgomery-Downs et al., 2010; Sharma et al., 2011; Bonamy et al., 2012; Bucher et al., 2012; Kerkhof et al., 2012). Therefore, further studies examining the CRC in preterm infants may prove to be useful in establishing measurements of CRC as an early diagnostic indicator for increased risk for cardiorespiratory collapse during apneic bouts or even cardiorespiratory disorders later in life. Moreover, additional work is clearly needed to further elucidate the neurophysiological consequence of prematurity on central autonomic cardiorespiratory control which may also provide key insights into understanding the development and CRC during the perinatal period.

\section{Sudden Infant Death Syndrome}

SIDS is the unexplained death of an infant less than one year of age during sleep (Krous et al., 2004). A wide range of factors from maternal behaviors such cigarette smoking and substance abuse (Iyasu et al., 2002; Blair et al., 2006; Horne, 2006; Moon et al., 2007; Moon, 2011) to sleeping conditions such as soft bedding and sleeping in the prone position (Willinger et al., 1994; Mitchell et al., 1999b; Mitchell et al., 1999a) have been identified with an increased risk for SIDS. Although, we have gained many new insights into the mechanistic basis of this syndrome, there are still many open questions (Morris, 1999; Kinney et al., 2009; Goldwater, 2011; Tfelt-Hansen et al., 2011). This complexity in the etiology of SIDS is readily exemplified by the shifts in SIDS demographic data. For example, in the UK, the proportion of SIDS occurrence in term infants have decreased but the proportion of SIDS occurrence in preterm infants rose from 12 to 34\% (Blair et al., 2006). Although it may not be surprising to find that preterm birth and low birth weight are associated with a 3-4 fold incidence of SIDS (Malloy and Freeman, 2000; Carpenter et al., 2004; Hoppenbrouwers et al., 2008), the increased risk of SIDS in preterm infants more closely correlates to the perinatal environment such as maternal smoking rather than to the presence of AoP (Malloy and Freeman, 2000; Dietz et al., 2010). Thus, in contrast to AoP which appears to involve primarily physiological immaturity, the etiology of SIDS is more complex and appears to involve pathological changes in addition to physiological immaturity that give rise to AoP.

Based on observations made in animal models and clinical observations made in both healthy normal infants and infants who later succumb to SIDS, SIDS appears to be the convergence of three general factors: environmental challenge, presence of an underlying vulnerability in the infant, and a critical period of development (Wedgwood, 1972; Rognum and Saugstad, 1993; Filiano and Kinney, 1994; Morris, 1999; Kinney et al., 2009). Environmental challenges correlating with SIDS include hypercapnic/hypoxic challenge. This type of challenge typically triggers arousal, which initializes protective airway responses and head turning that can ameliorate hypercapnic/hypoxic condition (Ayas et al., 2000; Thach, 2002; Masa et al., 2003; Parslow et al., 2003; Fewell, 2005; Horne et al., 2005). Prospective clinical studies, however, have found that alterations are present in the 
arousal response of children who succumb to SIDS (McCulloch et al., 1982; Dunne et al., 1992; Sawaguchi et al., 2005). In addition to the deficiencies in arousal, an inability to successfully auto-resuscitate during hypoxic challenge has also been documented in SIDS infants (Poets, 2004). Both successful arousal and auto-resuscitation involve respiratory and cardiac responses. Normal arousal is identified by the occurrence of sighs and the accompanying RSA while successful auto-rescusitation (i.e., gasping) is followed by progressive increases in HR (Thach and Lijowska, 1996; Lijowska et al., 1997; Thach, 2002; Wulbrand et al., 2008). The recognized behavioral deficiencies in infants that succumb to SIDS suggest altered CRC. However, the mechanisms underlying such an alteration remain unknown.

Postmortem analyses of brain tissue from SIDS victims have documented a variety of subtle yet significant abnomalities within the serotonergic neuromodulatory pathway, involving 5HT receptors, 5-HT transporters, and even a key biosynthetic 5-HT enzyme, tryptophan hydroxylase (Sawaguchi et al., 2005; Kinney et al., 2009). Given the role that serotonergic neuromodulation alters central autonomic cardiorespiratory control (see previous sections), subtle changes in this pathway may be a primary contributor leading to an infant vulnerability to SIDS. This is supported by recent animal studies where serotonergic neuromodulatory pathways are disrupted leading to altered cardio-respiratory homeostasis and altered thermoregulation (Cummings et al., 2009; Cummings et al., 2010; Cummings et al., 2011c; Cummings et al., 2011b; Cummings et al., 2011a). In the case of cardiorespiratory function, these studies have shown that disrupted serotinergic neuromodulation leads to an age-dependent development of spontaneous bradycardias which are associated with disruptions in respiration and a decrease in survival following episodic hypoxic challenge (Cummings et al., 2011c; Cummings et al., 2011b; Cummings et al., 2011a) These findings are also consistent with the observation that the generation of gasping critically depends on serotonin (Tryba et al., 2006) and the activation of persistent sodiumdependent pacemaker neurons (Pena et al., 2004), specific cellular mechanisms that take place within the medulla, and the pre-Bötzinger complex in particular (Lieske et al., 2000; Pena et al., 2004).

In addition to understanding potential consequences of serotinergic dysfunction in SIDS, an extensive effort has been placed on examining the basis by which environmental factors may also be involved. Perhaps the most prominent area investigating the basis of environmental contribution to SIDS, arises from work focused on the impact nicotine exposure. It is well established that nicotine exposure affects both peripheral and central components of cardiorespiratory control resulting in the alteration of the hypoxic ventilatory response from the normal biphasic response (i.e., augmentation transitioning to depression) to a monotonic response characterized by depression. We have focused this portion of the review on the effects of perinatal nicotine exposure on central aspects of cardiorespiratory control and coupling (for further review on this topic and related topics concerning perinatal nicotine exposure see Hafstörm et al. (2005) and Stéphan-Blanchard et al. (2013)). Perinatal nicotine exposure causes a switch from normal muscarinic receptor-based mechanisms to nicotinic receptor-based mechanisms and is accompanied by instability of brainstem respiratory activity including compromised central chemoreception (Eugenin et al. 2008). Similarly, perinatal nicotine exposure increases the strength of GABAergic input related to respiratory rhythmogenesis to $\mathrm{CVN}_{\mathrm{NA}}$ (Neff et al. 2004 and Huang et al. 2006). Furthermore, perinatal nicotine exposure also leads to a rapid monotonic decrease in GABAergic input to $\mathrm{CVN}_{\mathrm{NA}}$ (Neff et al. 2004), which may be the basis of the observed bradycardia during hypoxia in neonatal animal models exposed to nicotine in utero (Slotkin 1997). Thus, environmental factors such as perinatal nicotine appear to alter the mechanistic basis of CRC which potentially can lead to cardio-respiratory collapse during hypercapnic/hypoxic challenge and thus, contribute to SIDS. 


\section{Sleep disordered breathing}

During the majority of sleep, the body is a state of cardiovascular relaxation where metabolic rate, heart rate, and sympathetic tone are reduced (Somers et al., 1993) while vagal activity is increased (Van de Borne et al., 1994). However, in cases of sleep disordered breathing, such as obstructive sleep apnea (OSA), intermittent bouts of hypoxemia cause repeated arousals leading to sleep fragmentation, elevated sympathetic tone and increased oxidative stress (Somers et al., 2008). The occurrence of these changes appears to be involved in the mechanisms of several cardiovascular disease states. Thus, OSA has been implicated as a risk factor for hypertension, stroke, heart failure and sudden cardiac death (Bradley and Floras, 2003a; Somers et al., 2008; Bradley and Floras, 2009; Kuniyoshi et al., 2010).

The majority of hypothetical models for the basis of OSA implicate increased occurrence of arousal (Bradley and Floras, 2003a, 2009) and elevated production of ROS (Adhikary et al., 2001; Lavie et al., 2004; Yuan et al., 2004; Lavie and Lavie, 2009, 2012) as the two most prominent factors promoting the decline in cardiovascular health when OSA goes untreated. The increased occurrence of arousals due to IH disrupts the normal state of cardiovascular relaxation and to give rise to a persistent elevation in sympathetic tone extending beyond the sleep period into awake periods (Bradley and Floras, 2003b, a, 2009); whereas, increased ROS production has been identified as the source of oxidative stress (Adhikary et al., 2001; Lavie et al., 2004; Yuan et al., 2004; Lavie and Lavie, 2009, 2012). Thus, the occurrence of $\mathrm{IH}$ in untreated OSA is the origin of two separate potentially pathophysiological factors involved with the etiology of various declines cardiovascular health.

There is a growing perspective OSA may represent a unique state of transition from normally adaptive responses to maladaptive pathophysiological states. This may be best typified in the case of ROS production during OSA. While measureable increases in oxidative stress clearly represent the maladaptive role of increased ROS production, acute periods of ROS production in response to the IH early in the progression of untreated OSA may have a signaling role (Yin et al., 2012). This is experimentally supported by the ability for acute intermittent periods of hypoxia to confer protection during future hypoxic insults (Murry et al., 1986; Reimer et al., 1986; Stowe et al., 2011). Similarly, the IH-mediated induction of phrenic long term facilitation has been hypothesized to promote stabilization of airway patency (Mahamed and Mitchell, 2007) and also involves a ROS mechanism (MacFarlane et al., 2009). Furthermore, hydrogen peroxide, differentially affects rhythmogenesis in the preBötC, the inspiratory rhythm generator, compared to hydroxyl radicals, a predominant source of oxidative damage in biological systems (Garcia et al., 2011).

Similarly, arousal and the accompanying elevation in sympathetic tone during an initial hypoxemic event is advantageous as it ameliorates the progression into a sustained period of hypoxia, but chronic repeated arousals in OSA lead to sympathovagal imbalance (Bradley and Floras, 2003b, a). Increased sympathetic tone has been the predominant focus when studying sympathovagal imbalance during OSA, but there is also evidence to suggest that increased parasympathetic tone may also occur in untreated OSA. Specifically, the occurrence of bradycardiac arrhythmias in untreated OSA has not only been documented, but the severity of bradycardia correlates with the severity of apnea (Zwillich et al., 1982; Becker et al., 1998).

\section{Methods applying for quantitative analysis of HRV and RSA}

The behavior of the cardiovascular system and its coupling to the respiratory system is not only of great neurobiological and clinical interest, but it has all the characteristics of a 
nonlinear dynamical system that is amenable to a quantitative analysis. Indeed, by unraveling the nonlinear dynamics that underlie the cardiorespiratory control there is an immense opportunity to gain not only important basic-scientific insights into the interactions between these two rhythmically active networks, but perhaps even more importantly, such an understanding will provide important insights that allow us to better describe a given disease.

For example, Weese-Mayer et al., (2006) using the cross-correlation analysis evaluated the difference in time and frequency-series datasets collected from individuals suffering from Rett syndrome and from healthy individuals. The comparison of two different datasets shows the significant deviation of temporal characteristics characterizing cardiorespiratory interaction such as amplitude of respiratory frequency component, location of the first peak in heart frequency component in response to single breath, and amplitude of the first peak in heart frequency component in response to breathhold (Figure 4) (Weese-Mayer et al., 2006).

Detailed analysis of HRV including RSA through the use of different mathematical approaches may give us a better understanding on the unbalanced cardiorespiratory coupling that seems to present in individuals with Rett syndrome.

The physiological frequency and waveform patterns recorded from patients show very complex dynamics that are reflected in heart rate fluctuations. Heart rate variability HRV is defined as the chaotic oscillation in the duration of the R-R interval around its mean value. While changes in HVR are believed to represent changes in the state of cardiac health associated with changes in sympathetic and parasympathetic balance, the precise physiological basis of HRV still remains an open question. In humans, the heart rate oscillates between $0.003 \mathrm{~Hz}$ and $0.5 \mathrm{~Hz}$, and HRV is historically divided into three frequency ranges: very low frequency $(0.003-0.004) \mathrm{Hz}$, low frequency $(0.04-0.15) \mathrm{Hz}$, and high frequency $(0.15-0.5) \mathrm{Hz}$ components. Since the high frequency range is associated with respiration, the respiration-related instability observed within this frequency band is commonly used to describe RSA. A brief overview of the methodology commonly used to assess CRC from clinical data shows that no universal method is currently available to characterize all aspects of the temporal and spatial properties of HRV. Consequently no single method can establish criteria that unambiguously define the difference between healthy and unhealthy states. Thus, numerous methods have been developed to investigate different aspects of HRV or RSA. In this section we would like to discuss the strengths as well as the limitations of the most common methods that are used for the analysis of HRV.

A commonly used approach to characterize RSA is based on the difference between the cardiac and respiratory frequencies over the single breath and thus is dependent on acquisition of both cardiac and respiratory metrics. However, to avoid aliasing of the relationship between cardiac and respiratory frequencies a ratio of at least 2:1 is required. If this condition is not satisfied, RSA must be calculated over longer durations rather than a single breath. An alternative approach to evaluate RSA is to examine HRV within the high frequency range using only cardiac datasets as respiratory frequency is typically found in the high frequency domain.

The lack of fluctuation in HR or decreased HRV is indicative for some degree of heart failure in patients. Common diagnostic methods to analyze HVR have employed either timeseries data in order to determine standard deviation of the R-R intervals (Kleiger et al., 1987; Kawachi et al., 1995) or frequency-series data in order to perform power spectral analysis (Akselrod et al., 1981; Yeragani et al., 1993; Kristal-Boneh et al., 1995). Heart rate dynamics are typically more chaotic during daytime recording which is thought to be due to a significant increase of sympathetic drive. Based on this assumption, HR recordings are 
often performed during nighttime which is thought to provide better insights into the parasympathetic drive. The increase of RSA during the night has been previously reported in healthy individuals (Carroll et al., 2012). Comparison of control individuals to a cohort with familial dysautonomia demonstrates the significant reduction of RSA in individuals with familial dysautonomia (Figure 5). In Carroll et al. (2012) study RSA magnitude was calculated as the mean value of the difference between the two R-R intervals (the longest and the shortest) within a single breath. Similar to healthy individuals, the increase of RSA magnitude during night time was also observed in people with familial dysautonomia (Carroll et al., 2012). Unfortunately, in many cases the standard deviation of R-R interval in healthy and sick patients is undistinguishable which introduces a high degree of uncertainty for this approach. On the other hand, an alternative approach, for example power spectral analysis may also be ineffective if a patient exhibits HR arrhythmia causing an increase in HRV. Thus, there is an obvious need for novel analytical approaches to assess healthy versus diseased HRV.

\section{$1 / f$ spectrum analysis}

This approach determines the frequency dependency of HRV, which is inversely proportional to frequency. Thus, this approach referred to as $1 / \mathrm{f}$ fluctuations or $1 / \mathrm{f}$ spectrum analysis. The inverse frequency dependency is a defining characteristic of a system that exhibits repetitive patterns also known as fractal-like behavior (Kobayashi and Musha, 1982; Bassingthwaighte et al., 1994). The 1/f spectrum is most effective for HR fluctuations in the very low and low frequency range. For instance, the slope value of the function describing the dependency of $\log$ (power spectral density) vs log (frequency) can be used to predict the heart failure after myocardial infarction (Bigger et al., 1996). However, this method requires a large data set and its application may not be valid for high frequency range, thus limiting its utility for RSA analysis.

\section{Entropy calculations}

The method of calculated entropy is specifically used to characterize the measure of disorder of the system. Large entropy values correspond to greater irregularities in behavior of a given system. This approach has been widely used to analyze HRV including RSA by calculating either Shannon entropy, approximate entropy (Larsen and Galletly, 2001) or applying transfer entropy analysis, which characterizes the exchange of information between respiratory and heart rate oscillators (Schreiber, 2000). For example, the method of approximate entropy calculates the single value that characterizes the regularity and predictability of the time-series data. Time-series data containing repetitive events with minimal fluctuation gives a small value of approximate entropy that indicates abnormality in HR dynamics. However, this approach is limited by its sensitivity to noise, therefore to accurately calculate approximate entropy the dataset has to be fairly stationary (Pincus, 1991).

\section{Poincare plot representation}

Poincare plot analysis was adopted from the theory of nonlinear dynamics, and is commonly used to analyze HRV including RSA (Brennan et al., 2001; Galletly and Larsen, 2001). Plotting the interval from the time-series $\left(R-R_{n}\right.$ interval) as a function of the following interval ( $R-R_{n+1}$ interval) creates the geometric representation of the dataset. This plot is quantitatively described by the width and the length of the data dispersion near the identity line (i.e. $45^{\circ}$ line). The standard deviation perpendicular (SD1) to the identity line characterizes short-term variability while the standard deviation scattered along the identity line (SD2) determines long term variability. Since SD1 and SD2 values depend on R-R interval, the ratio of SD1 to SD2 is used to make comparison among Poincare plots from different subjects. Thus, the comparison of plots from healthy and unhealthy individuals 
shows the geometrical difference in the degree of data dispersion. Poincare plot analysis relies on cumulative dispersion of data points and therefore complex plots containing multiple clusters can be overlooked by this analysis. Another recognized limitation of this approach is the loss of temporal correlation between dataset points. Fishman et al., (2012) proposed the use of temporal Poincare variability (TPV) analysis that compliments the standard Poincare plot analysis and allows one to resolve these issues (Fishman et al., 2012).

\section{Detrended fluctuation analysis}

This approach has also been used to quantify HRV (Peng et al., 1995). Detrended fluctuation analysis allows the detection of fractal-like HR dynamics that is characterized by a scaling exponent. The loss of fractal-like HR dynamics may indicate a divergence from normal HR behavior (Peng et al., 1995). For example, patients suffering from cardiovascular disease show smaller values of the scaling exponent (Makikallio et al., 2001). When the signal cannot be described by detrended fluctuation analysis because of its complexity, HRV complex dynamics can be achieved by multifractal representation. In the case of multifractal representation HRV is characterized not by one but multiple scaling exponents (Ivanov et al., 1999). The loss of multifractal heart rate dynamics can be a detector of congestive heart failure.

\section{Fast Fourier transformation}

At night, the heart rate dynamics are less chaotic and allow the use of standard techniques like fast Fourier transformation. This method decomposes the frequency-series data into components of different frequencies. However, the application of Fourier transformation analysis has some inherent limitations. For example, Cnockaert et al. (2008) pointed out that this approach cannot distinguish between low and high frequency values when respiratory frequency is less than $0.2 \mathrm{~Hz}$. Under these conditions, continuous wave transform analysis seems to be the better approach. Using artificially generated cardiac and respiratory data that were modeled with low frequency and fast variation representing the dynamics of RSA during nighttime, Cnockaert at el (2008) showed that the resolution of the data were better described by continuous wave transform analysis when compared to Fourier analysis (Cnockaert et al., 2008).

\section{Kramers-Moyal coefficients analysis}

Other approaches have been proposed to understand the nature of RSA to distinguish healthy from unhealthy conditions. One of them is based on the calculation of KramersMoyal coefficients such that the functional shape of them provides information about interactions between respiratory and heart beat oscillators (Buchner et al., 2009). This analysis is based on the assumption that HR can be considered as a stochastic process with Gaussian noise. Thus, HRV can be described by the Langevin equation $X^{\prime}(t)=D 1(X, t)$ $+\operatorname{sqrt}(2 \mathrm{D} 2(\mathrm{X}, \mathrm{t})) \Gamma(\mathrm{t})$, where $\mathrm{X}(\mathrm{t})$ is time-series data, $\Gamma(\mathrm{t})$ is Gaussian noise with zero mean value, $\mathrm{D} 1(\mathrm{X}, \mathrm{t})$ and $\mathrm{D} 2(\mathrm{X}, \mathrm{t})$ are first and second order coefficients of Kramers-Moyal expansion (Buchner et al., 2009; Petelczyc et al., 2009). By extracting from the data first $\mathrm{D} 1(\mathrm{X}, \mathrm{t})$ and second $\mathrm{D} 2(\mathrm{X}, \mathrm{t})$ terms, and neglecting the higher order term due to its small value, the HRV can be reconstructed through the Langevin equation (Tabar et al., 2006). It provides an opportunity to use this method for modeling of HRV. The calculation of the Kramers-Moyal expansion terms by itself can be a powerful method in characterizing heart rate. For instance, the shape of the functional term $\mathrm{D} 2(\mathrm{X}, \mathrm{t})$ is asymmetric in healthy patients, but $\mathrm{D} 2(\mathrm{X}, \mathrm{t})$ calculated in patients with hypertrophic cardiomyopathy does not possess asymmetric shape (Petelczyc et al., 2009). Petelczyc et al. (2009) also showed that data from the nighttime recording has none-zero higher order $\left(3^{\text {rd }}\right.$ and $\left.4^{\text {th }}\right)$ Kramers-Moyal terms and the appearance of these terms is suggested to relate to the effect of respiration on the HR. 
By using a similar approach, Buchner et al. in 2009 analyzed polysomnographic recordings and calculated Kramers-Moyal expansion terms from nighttime data series of respiration and heart beat oscillators. The authors predicted that coupling of two independent autonomous systems such as respiratory and heart oscillators may underlie the nature of the HRV (Petelczyc et al., 2009). Moreover, the D1(X,t) and D2(X,t) terms shape analysis of respiratory and heart beat traces predicts that neither of two oscillators may be considered as a dominant, meaning that they equally contribute to the heart rate variability.

\section{Conclusion}

CRC has many potential benefits as it creates synergy between the cardiovascular and respiratory systems. CRC, such as RSA, appears to originate from the brainstem and results from interactions between $\mathrm{CVN}_{\mathrm{NA}}$ and neuronal networks, like the preBötC, an area essential for the central control of respiration. While RSA is readily seen in healthy people, cardiorespiratory dysautonomia is characteristic for several disease states. A decline in CRC involves several biological mechanisms that appear to converge onto cardiorespiratory functions that predominantly originate within the brainstem. However, while much has been learned over the past decade, we are still far away from a complete understanding of both normal and pathophysiological interactions that respectively give rise to CRC and cardiorespiratory dysautonomia. The need for a better mechanistic understanding is paralleled by the need for better quantitative methods that can be used to assess CRC. Current approaches measuring HRV provide useful insights into CRC but these approaches are not without limitation. Thus, working to understand CRC from both a mechanistic perspective and from a perspective that quantitatively measures CRC may lead to: (1) future treatments that may reduce or eliminate cardiorespiratory dysautnomia; (2) better assessing the degree of decline of CRC in disease states thereby potential providing additional avenues for treatment of disease; and (3) recognizing populations susceptible to cardiorespiratory dysautonomia while still asymptomatic of disease.

\section{References}

Abdala AP, Dutschmann M, Bissonnette JM, Paton JF. Correction of respiratory disorders in a mouse model of Rett syndrome. Proc Natl Acad Sci U S A. 2010; 107:18208-18213. [PubMed: 20921395]

Abu-Shaweesh JM, Martin RJ. Neonatal apnea: what's new? Pediatr Pulmonol. 2008; 43:937-944. [PubMed: 18780339]

Adhikary G, Kline D, Yuan G, Kumar GK, Simonson MS, Cherniack NS, Prabhakar NR. Gene regulation during intermittent hypoxia: evidence for the involvement of reactive oxygen species. Adv Exp Med Biol. 2001; 499:297-302. [PubMed: 11729895]

Aizad T, Bodani J, Cates D, Horvath L, Rigatto H. Effect of a single breath of $100 \%$ oxygen on respiration in neonates during sleep. J Appl Physiol. 1984; 57:1531-1535. [PubMed: 6520049]

Akselrod S, Gordon D, Ubel FA, Shannon DC, Berger AC, Cohen RJ. Power spectrum analysis of heart rate fluctuation: a quantitative probe of beat-to-beat cardiovascular control. Science. 1981; 213:220-222. [PubMed: 6166045]

Al-Matary A, Kutbi I, Qurashi M, Khalil M, Alvaro R, Kwiatkowski K, Cates D, Rigatto H. Increased peripheral chemoreceptor activity may be critical in destabilizing breathing in neonates. Semin Perinatol. 2004; 28:264-272. [PubMed: 15565786]

Alvarez JE, Baier RJ, Fajardo CA, Nowaczyk BJ, Cates DB, Rigatto H. The effect of $10 \%$ O2 on the continuous breathing induced by $\mathrm{O} 2$ or $\mathrm{O} 2$ plus cord occlusion in the fetal sheep. J Dev Physiol. 1992; 17:227-232. [PubMed: 1460247]

Alvaro R, Alvarez J, Kwiatkowski K, Cates D, Rigatto H. Small preterm infants (less than or equal to $1500 \mathrm{~g}$ ) have only a sustained decrease in ventilation in response to hypoxia. Pediatr Res. 1992; 32:403-406. [PubMed: 1437391] 
Anrep GV, Pascual FRS, Rossler R. Respiratory Variations of the Heart Rate. II. The Central Mechanism of Respiratory Arrhythmia and the Inter-Relations between the Central and Reflex Mechanisms. Proceedings of the Royal Society (Proc R Soc Lond). 1936; 119:218-230.

Ayas NT, Brown R, Shea SA. Hypercapnia can induce arousal from sleep in the absence of altered respiratory mechanoreception. Am J Respir Crit Care Med. 2000; 162:1004-1008. [PubMed: 10988121]

Barrington KJ, Finer NN. Periodic breathing and apnea in preterm infants. Pediatr Res. 1990; 27:118121. [PubMed: 2314939]

Bassingthwaighte, JB.; Liebovitch, LS.; West, BJ. Fractal Physiology. New York: Oxford University Press; 1994.

Bateman RJ, Boychuk CR, Philbin KE, Mendelowitz D. beta adrenergic receptor modulation of neurotransmission to cardiac vagal neurons in the nucleus ambiguus. Neuroscience. 2012; 210:5866. [PubMed: 22425752]

Becker HF, Koehler U, Stammnitz A, Peter JH. Heart block in patients with sleep apnoea. Thorax. 1998; 53(Suppl 3):S29-32. [PubMed: 10193358]

Ben-Tal A, Shamailov SS, Paton JF. Evaluating the physiological significance of respiratory sinus arrhythmia: looking beyond ventilation-perfusion efficiency. J Physiol. 2012; 590:1989-2008. [PubMed: 22289913]

Bigger JT Jr, Steinman RC, Rolnitzky LM, Fleiss JL, Albrecht P, Cohen RJ. Power law behavior of RR-interval variability in healthy middle-aged persons, patients with recent acute myocardial infarction, and patients with heart transplants. Circulation. 1996; 93:2142-2151. [PubMed: 8925583]

Bissonnette JM. Mechanisms regulating hypoxic respiratory depression during fetal and postnatal life. Am J Physiol Regul Integr Comp Physiol. 2000; 278:R1391-1400. [PubMed: 10848503]

Blair PS, Sidebotham P, Berry PJ, Evans M, Fleming PJ. Major epidemiological changes in sudden infant death syndrome: a 20-year population-based study in the UK. Lancet. 2006; 367:314-319. [PubMed: 16443038]

Boddy K, Dawes GS, Fisher R, Pinter S, Robinson JS. Foetal respiratory movements, electrocortical and cardiovascular responses to hypoxaemia and hypercapnia in sheep. J Physiol. 1974; 243:599618. [PubMed: 4475694]

Bonamy AK, Kallen K, Norman M. High blood pressure in 2.5-year-old children born extremely preterm. Pediatrics. 2012; 129:e1199-1204. [PubMed: 22473369]

Boychuk CR, Bateman RJ, Philbin KE, Mendelowitz D. alpha1-adrenergic receptors facilitate inhibitory neurotransmission to cardiac vagal neurons in the nucleus ambiguus. Neuroscience. 2011; 193:154-161. [PubMed: 21771639]

Bradley TD, Floras JS. Sleep apnea and heart failure: Part I: obstructive sleep apnea. Circulation. 2003a; 107:1671-1678. [PubMed: 12668504]

Bradley TD, Floras JS. Sleep apnea and heart failure: Part II: central sleep apnea. Circulation. 2003b; 107:1822-1826. [PubMed: 12682029]

Bradley TD, Floras JS. Obstructive sleep apnoea and its cardiovascular consequences. Lancet. 2009; 373:82-93. [PubMed: 19101028]

Brennan M, Palaniswami M, Kamen P. Do existing measures of Poincare plot geometry reflect nonlinear features of heart rate variability? IEEE Trans Biomed Eng. 2001; 48:1342-1347. [PubMed: 11686633]

Bucher BS, Tschumi S, Simonetti GD. Childhood's determinants for high blood pressure in adulthood. Ther Umsch. 2012; 69:295-298. [PubMed: 22547361]

Buchner T, Petelczyc M, Zebrowski JJ, Prejbisz A, Kabat M, Januszewicz A, Piotrowska AJ, Szelenberger W. On the nature of heart rate variability in a breathing normal subject: a stochastic process analysis. Chaos. 2009; 19:028504. [PubMed: 19566279]

Carpenter RG, Irgens LM, Blair PS, England PD, Fleming P, Huber J, Jorch G, Schreuder P. Sudden unexplained infant death in 20 regions in Europe: case control study. Lancet. 2004; 363:185-191. [PubMed: 14738790]

Carroll JL, Kim I. Postnatal development of carotid body glomus cell O2 sensitivity. Respir Physiol Neurobiol. 2005; 149:201-215. [PubMed: 15886071] 
Carroll JL, Agarwal A. Development of ventilatory control in infants. Paediatr Respir Rev. 2010; 11:199-207. [PubMed: 21109177]

Carroll JL, Bamford OS, Fitzgerald RS. Postnatal maturation of carotid chemoreceptor responses to O2 and CO2 in the cat. J Appl Physiol. 1993; 75:2383-2391. [PubMed: 8125854]

Carroll MS, Kenny AS, Patwari PP, Ramirez JM, Weese-Mayer DE. Respiratory and cardiovascular indicators of autonomic nervous system dysregulation in familial dysautonomia. Pediatr Pulmonol. 2012; 47:682-691. [PubMed: 22170819]

Cazzola M, Calzetta L, Bettoncelli G, Cricelli C, Romeo F, Matera MG, Rogliani P. Cardiovascular disease in asthma and COPD: a population-based retrospective cross-sectional study. Respir Med. 2012; 106:249-256. [PubMed: 21856140]

Chao HT, Chen H, Samaco RC, Xue M, Chahrour M, Yoo J, Neul JL, Gong S, Lu HC, Heintz N, Ekker M, ubenstein JL, Noebels JL, Rosenmund C, Zoghbi HY. Dysfunction in GABA signalling mediates autism-like stereotypies and Rett syndrome phenotypes. Nature. 2010; 468:263-269. [PubMed: 21068835]

Chardon K, Telliez F, Bach V, Leke A, Delanaud S, Bouferrache B, Libert JP, Gaultier C. Effects of warm and cool thermal conditions on ventilatory responses to hyperoxic test in neonates. Respir Physiol Neurobiol. 2004; 140:145-153. [PubMed: 15134662]

Cnockaert L, Migeotte PF, Daubigny L, Prisk GK, Grenez F, Sa RC. A method for the analysis of respiratory sinus arrhythmia using continuous wavelet transforms. IEEE Trans Biomed Eng. 2008; 55:1640-1642. [PubMed: 18440911]

Colin AA, McEvoy C, Castile RG. Respiratory morbidity and lung function in preterm infants of 32 to 36 weeks' gestational age. Pediatrics. 2010; 126:115-128. [PubMed: 20530073]

Costa-Silva JH, Zoccal DB, Machado BH. Glutamatergic antagonism in the NTS decreases postinspiratory drive and changes phrenic and sympathetic coupling during chemoreflex activation. J Neurophysiol. 2010; 103:2095-2106. [PubMed: 20164386]

Cross KW, Oppe TE. The effect of inhalation of high and low concentrations of oxygen on the respiration of the premature infant. J Physiol. 1952; 117:38-55. [PubMed: 14946728]

Cummings KJ, Li A, Nattie EE. Brainstem serotonin deficiency in the neonatal period: autonomic dysregulation during mild cold stress. J Physiol. 2011a; 589:2055-2064. [PubMed: 21486799]

Cummings KJ, Li A, Deneris ES, Nattie EE. Bradycardia in serotonin-deficient Pet-1-/- mice: influence of respiratory dysfunction and hyperthermia over the first 2 postnatal weeks. Am J Physiol Regul Integr Comp Physiol. 2010; 298:R1333-1342. [PubMed: 20421636]

Cummings KJ, Commons KG, Fan KC, Li A, Nattie EE. Severe spontaneous bradycardia associated with respiratory disruptions in rat pups with fewer brain stem 5-HT neurons. Am J Physiol Regul Integr Comp Physiol. 2009; 296:R1783-1796. [PubMed: 19369586]

Cummings KJ, Hewitt JC, Li A, Daubenspeck JA, Nattie EE. Postnatal loss of brainstem serotonin neurones compromises the ability of neonatal rats to survive episodic severe hypoxia. J Physiol. 2011b; 589:5247-5256. [PubMed: 21911619]

Cummings KJ, Commons KG, Hewitt JC, Daubenspeck JA, Li A, Kinney HC, Nattie EE. Failed heart rate recovery at a critical age in 5-HT-deficient mice exposed to episodic anoxia: implications for SIDS. J Appl Physiol. 2011c; 111:825-833. [PubMed: 21680874]

Daly MD. Some reflex cardioinhibitory responses in the cat and their modulation by central inspiratory neuronal activity. J Physiol. 1991; 439:559-577. [PubMed: 1895245]

Dergacheva O, Griffioen KJ, Neff RA, Mendelowitz D. Respiratory modulation of premotor cardiac vagal neurons in the brainstem. Respir Physiol Neurobiol. 2010; 174:102-110. [PubMed: 20452467]

Dergacheva O, Kamendi H, Wang X, Pinol RM, Frank J, Jameson H, Gorini C, Mendelowitz D. The role of 5-HT3 and other excitatory receptors in central cardiorespiratory responses to hypoxia: implications for sudden infant death syndrome. Pediatr Res. 2009; 65:625-630. [PubMed: 19247214]

Deshpande P, Khurana A, Hansen P, Wilkins D, Thach BT. Failure of autoresuscitation in weanling mice: significance of cardiac glycogen and heart rate regulation. J Appl Physiol. 1999; 87:203210. [PubMed: 10409576] 
Di Fiore JM, Arko MK, Miller MJ, Krauss A, Betkerur A, Zadell A, Kenney SR, Martin RJ. Cardiorespiratory events in preterm infants referred for apnea monitoring studies. Pediatrics. 2001; 108:1304-1308. [PubMed: 11731652]

Dick TE, Baekey DM, Paton JF, Lindsey BG, Morris KF. Cardio-respiratory coupling depends on the pons. Respir Physiol Neurobiol. 2009; 168:76-85. [PubMed: 19643216]

Dietz PM, England LJ, Shapiro-Mendoza CK, Tong VT, Farr SL, Callaghan WM. Infant morbidity and mortality attributable to prenatal smoking in the U.S. Am J Prev Med. 2010; 39:45-52. [PubMed: 20547278]

Donnelly DF, Bavis RW, Kim I, Dbouk HA, Carroll JL. Time course of alterations in pre- and postsynaptic chemoreceptor function during developmental hyperoxia. Respir Physiol Neurobiol. 2009; 168:189-197. [PubMed: 19465165]

Dunne KP, Fox GP, O'Regan M, Matthews TG. Arousal responses in babies at risk of sudden infant death syndrome at different postnatal ages. Ir Med J. 1992; 85:19-22. [PubMed: 1568841]

Eckberg DL. Point:counterpoint: respiratory sinus arrhythmia is due to a central mechanism vs. respiratory sinus arrhythmia is due to the baroreflex mechanism. J Appl Physiol. 2009; 106:1740 1742. discussion 1744. [PubMed: 18719228]

Eichenwald EC, Aina A, Stark AR. Apnea frequently persists beyond term gestation in infants delivered at 24 to 28 weeks. Pediatrics. 1997; 100:354-359. [PubMed: 9282705]

Eugenín J, Otárola M, Bravo E, Coddou C, Cerpa V, Reyes-Parada M, Llona I, von Bernhardi R. Prenatal to early postnatal nicotine exposure impairs central chemoreception and modifies breathing pattern in mouse neonates: a probable line to sudden infant death syndrome. J Neurosci. 2008; 28:13907-13917. [PubMed: 19091979]

Evans C, Wang J, Neff R, Mendelowitz D. Hypoxia recruits a respiratory-related excitatory pathway to brainstem premotor cardiac vagal neurons in animals exposed to prenatal nicotine. Neuroscience. 2005; 133:1073-1079. [PubMed: 15964492]

Fewell JE. Protective responses of the newborn to hypoxia. Respir Physiol Neurobiol. 2005; 149:243255. [PubMed: 15941675]

Filiano JJ, Kinney HC. A perspective on neuropathologic findings in victims of the sudden infant death syndrome: the triple-risk model. Biol Neonate. 1994; 65:194-197. [PubMed: 8038282]

Fishman M, Jacono FJ, Park S, Jamasebi R, Thungtong A, Loparo KA, Dick TE. A method for analyzing temporal patterns of variability of a time series from Poincare plots. J Appl Physiol. 2012; 113:297-306. [PubMed: 22556398]

Franco P, Szliwowski H, Dramaix M, Kahn A. Polysomnographic study of the autonomic nervous system in potential victims of sudden infant death syndrome. Clin Auton Res. 1998; 8:243-249. [PubMed: 9801844]

Franco P, Verheulpen D, Valente F, Kelmanson I, de Broca A, Scaillet S, Groswasser J, Kahn A. Autonomic responses to sighs in healthy infants and in victims of sudden infant death. Sleep Med. 2003; 4:569-577. [PubMed: 14607352]

Galletly DC, Larsen PD. Cardioventilatory coupling in heart rate variability: methods for qualitative and quantitative determination. Br J Anaesth. 2001; 87:827-833. [PubMed: 11878682]

Garcia AJ 3rd, Khan SA, Kumar GK, Prabhakar NR, Ramirez JM. Hydrogen peroxide differentially affects activity in the pre-Botzinger complex and hippocampus. J Neurophysiol. 2011; 106:30453055. [PubMed: 21849609]

Gauda EB, Carroll JL, Donnelly DF. Developmental maturation of chemosensitivity to hypoxia of peripheral arterial chemoreceptors--invited article. Adv Exp Med Biol. 2009; 648:243-255. [PubMed: 19536487]

Gauda EB, McLemore GL, Tolosa J, Marston-Nelson J, Kwak D. Maturation of peripheral arterial chemoreceptors in relation to neonatal apnoea. Semin Neonatol. 2004; 9:181-194. [PubMed: 15050211]

Gilbey MP, Jordan D, Richter DW, Spyer KM. Synaptic mechanisms involved in the inspiratory modulation of vagal cardio-inhibitory neurones in the cat. J Physiol. 1984; 356:65-78. [PubMed: 6520798]

Glotzbach SF, Tansey PA, Baldwin RB, Ariagno RL. Periodic breathing cycle duration in preterm infants. Pediatr Res. 1989a; 25:258-261. [PubMed: 2704592] 
Glotzbach SF, Baldwin RB, Lederer NE, Tansey PA, Ariagno RL. Periodic breathing in preterm infants: incidence and characteristics. Pediatrics. 1989b; 84:785-792. [PubMed: 2797974]

Goldwater PN. A perspective on SIDS pathogenesis. the hypotheses: plausibility and evidence. BMC Med. 2011; 9:64. [PubMed: 21619576]

Granata AR, Cohen MI. Different types of barosensory synaptic inputs to rostral ventrolateral medulla neurons of the rat. Brain Res. 2004; 998:36-47. [PubMed: 14725966]

Gray PA, Janczewski WA, Mellen N, McCrimmon DR, Feldman JL. Normal breathing requires preBotzinger complex neurokinin-1 receptor-expressing neurons. Nat Neurosci. 2001; 4:927-930. [PubMed: 11528424]

Gray PA, Hayes JA, Ling GY, Llona I, Tupal S, Picardo MC, Ross SE, Hirata T, Corbin JG, Eugenin J, Del Negro CA. Developmental origin of preBotzinger complex respiratory neurons. J Neurosci. 2010; 30:14883-14895. [PubMed: 21048147]

Griffioen KJ, Gorini C, Jameson H, Mendelowitz D. Purinergic P2X receptors mediate excitatory transmission to cardiac vagal neurons in the nucleus ambiguus after hypoxia. Hypertension. 2007; 50:75-81. [PubMed: 17470721]

Groome LJ, Mooney DM, Bentz LS, Wilson JD. Vagal tone during quiet sleep in normal human term fetuses. Dev Psychobiol. 1994a; 27:453-466. [PubMed: 7843499]

Groome LJ, Mooney DM, Bentz LS, Singh KP. Spectral analysis of heart rate variability during quiet sleep in normal human fetuses between 36 and 40 weeks of gestation. Early Hum Dev. 1994b; 38:1-9. [PubMed: 7982383]

Guideri F, Acampa M, Hayek G, Zappella M, DiPerri T. Reduced heart rate variability in patients affected with Rett syndrome: a possible explanation for sudden death. Neuropediatrics. 1999; 30:146-148. [PubMed: 10480210]

Guideri F, Acampa M, DiPerri T, Zappella M, Hayek Y. Progressive cardiac dysautonomia observed in patients affected by classic Rett Syndrome and not in the preserved speech variant. J Child Neurol. 2001; 16:370-373. [PubMed: 11392524]

Gustafson KM, Allen JJ, Yeh HW, May LE. Characterization of the fetal diaphragmatic magnetomyogram and the effect of breathing movements on cardiac metrics of rate and variability. Early Hum Dev. 2011; 87:467-475. [PubMed: 21497027]

Gustafson KM, May LE, Yeh HW, Million SK, Allen JJ. Fetal cardiac autonomic control during breathing and non-breathing epochs: the effect of maternal exercise. Early Hum Dev. 2012; 88:539-546. [PubMed: 22264436]

Guyenet PG, Koshiya N. Working model of the sympathetic chemoreflex in rats. Clin Exp Hypertens. 1995; 17:167-179. [PubMed: 7735267]

Hafström O, Milerad J, Sandberg KL, Sundell HW. Cardiorespiratory effects of nicotine exposure during development. Respir Physiol Neurobiol. 2005; 149:325-341. [PubMed: 15970470]

Haider AZ, Rehan V, Al-Saedi S, Alvaro R, Kwiatkowski K, Cates D, Rigatto H. Effect of baseline oxygenation on the ventilatory response to inhaled $100 \%$ oxygen in preterm infants. J Appl Physiol. 1995; 79:2101-2105. [PubMed: 8847279]

Harper RM, Walter DO, Leake B, Hoffman HJ, Sieck GC, Sterman MB, Hoppenbrouwers T, Hodgman J. Development of sinus arrhythmia during sleeping and waking states in normal infants. Sleep. 1978; 1:33-48. [PubMed: 227022]

Hayano J, Yasuma F, Okada A, Mukai S, Fujinami T. Respiratory sinus arrhythmia. A phenomenon improving pulmonary gas exchange and circulatory efficiency. Circulation. 1996; 94:842-847. [PubMed: 8772709]

Hill AA, Garcia AJ 3rd, Zanella S, Upadhyaya R, Ramirez JM. Graded reductions in oxygenation evoke graded reconfiguration of the isolated respiratory network. J Neurophysiol. 2011; 105:625639. [PubMed: 21084689]

Hoppenbrouwers T, Hodgman JE, Ramanathan A, Dorey F. Extreme and conventional cardiorespiratory events and epidemiologic risk factors for SIDS. J Pediatr. 2008; 152:636-641. [PubMed: 18410765]

Hoppenbrouwers T, Hodgman JE, Harper RM, Hofmann E, Sterman MB, McGinty DJ. Polygraphic studies of normal infants during the first six months of life: III. Incidence of apnea and periodic breathing. Pediatrics. 1977; 60:418-425. [PubMed: 905004] 
Horne RS. Effects of prematurity on heart rate control: implications for sudden infant death syndrome. Expert Rev Cardiovasc Ther. 2006; 4:335-343. [PubMed: 16716094]

Horne RS, Parslow PM, Harding R. Postnatal development of ventilatory and arousal responses to hypoxia in human infants. Respir Physiol Neurobiol. 2005; 149:257-271. [PubMed: 15876558]

Irnaten M, Neff RA, Wang J, Loewy AD, Mettenleiter TC, Mendelowitz D. Activity of cardiorespiratory networks revealed by transsynaptic virus expressing GFP. J Neurophysiol. 2001; 85:435-438. [PubMed: 11152744]

Ivanov PC, Amaral LA, Goldberger AL, Havlin S, Rosenblum MG, Struzik ZR, Stanley HE. Multifractality in human heartbeat dynamics. Nature. 1999; 399:461-465. [PubMed: 10365957]

Iyasu S, Randall LL, Welty TK, Hsia J, Kinney HC, Mandell F, McClain M, Randall B, Habbe D, Wilson $\mathrm{H}$, Willinger M. Risk factors for sudden infant death syndrome among northern plains Indians. Jama. 2002; 288:2717-2723. [PubMed: 12460095]

Jameson HS, Pinol RA, Mendelowitz D. Purinergic P2X receptors facilitate inhibitory GABAergic and glycinergic neurotransmission to cardiac vagal neurons in the nucleus ambiguus. Brain Res. 2008; 1224:53-62. [PubMed: 18590708]

Kahn A, Blum D, Rebuffat E, Sottiaux M, Levitt J, Bochner A, Alexander M, Grosswasser J, Muller MF. Polysomnographic studies of infants who subsequently died of sudden infant death syndrome. Pediatrics. 1988; 82:721-727. [PubMed: 3186351]

Karemaker JM. Counterpoint: respiratory sinus arrhythmia is due to the baroreflex mechanism. J Appl Physiol. 2009a; 106:1742-1743. discussion 1744. [PubMed: 19414625]

Karemaker JM. Last word on point:counterpoint: respiratory sinus arrhythmia is due to a central mechanism vs. respiratory sinus arrhythmia is due to the baroreflex mechanism. J Appl Physiol. 2009b; 106:1750. [PubMed: 19265067]

Kawachi I, Sparrow D, Vokonas PS, Weiss ST. Decreased heart rate variability in men with phobic anxiety (data from the Normative Aging Study). Am J Cardiol. 1995; 75:882-885. [PubMed: 7732994]

Kerkhof GF, Breukhoven PE, Leunissen RW, Willemsen RH, Hokken-Koelega AC. Does preterm birth influence cardiovascular risk in early adulthood? J Pediatr. 2012; 161:390-396 e391. [PubMed: 22578582]

Kinney HC, Richerson GB, Dymecki SM, Darnall RA, Nattie EE. The brainstem and serotonin in the sudden infant death syndrome. Annu Rev Pathol. 2009; 4:517-550. [PubMed: 19400695]

Kleiger RE, Miller JP, Bigger JT Jr, Moss AJ. Decreased heart rate variability and its association with increased mortality after acute myocardial infarction. Am J Cardiol. 1987; 59:256-262. [PubMed: 3812275]

Kobayashi M, Musha T. 1/f fluctuation of heartbeat period. IEEE Trans Biomed Eng. 1982; 29:456457. [PubMed: 7106796]

Kristal-Boneh E, Raifel M, Froom P, Ribak J. Heart rate variability in health and disease. Scand J Work Environ Health. 1995; 21:85-95. [PubMed: 7618063]

Krous HF, Beckwith JB, Byard RW, Rognum TO, Bajanowski T, Corey T, Cutz E, Hanzlick R, Keens TG, Mitchell EA. Sudden infant death syndrome and unclassified sudden infant deaths: a definitional and diagnostic approach. Pediatrics. 2004; 114:234-238. [PubMed: 15231934]

Kuniyoshi FH, Pusalavidyasagar S, Singh P, Somers VK. Cardiovascular consequences of obstructive sleep apnoea. Indian J Med Res. 2010; 131:196-205. [PubMed: 20308745]

Kunze DL. Reflex discharge patterns of cardiac vagal efferent fibres. J Physiol. 1972; 222:1-15. [PubMed: 4338691]

Larsen PD, Galletly DC. Cardioventilatory coupling in heart rate variability: the value of standard analytical techniques. Br J Anaesth. 2001; 87:819-826. [PubMed: 11878681]

Lavie L, Lavie P. Molecular mechanisms of cardiovascular disease in OSAHS: the oxidative stress link. Eur Respir J. 2009; 33:1467-1484. [PubMed: 19483049]

Lavie L, Lavie P. CrossTalk opposing view: Most cardiovascular diseases in sleep apnoea are not caused by sympathetic activation. J Physiol. 2012; 590:2817-2819. discussion 2821. [PubMed: 22707584]

Lavie L, Vishnevsky A, Lavie P. Evidence for lipid peroxidation in obstructive sleep apnea. Sleep. 2004; 27:123-128. [PubMed: 14998248] 
Lemke RP, Idiong N, Al-Saedi S, Kwiatkowski K, Cates DB, Rigatto H. Evidence of a critical period of airway instability during central apneas in preterm infants. Am J Respir Crit Care Med. 1998; 157:470-474. [PubMed: 9476860]

Lieske SP, Thoby-Brisson M, Telgkamp P, Ramirez JM. Reconfiguration of the neural network controlling multiple breathing patterns: eupnea, sighs and gasps [see comment]. Nat Neurosci. 2000; 3:600-607. [PubMed: 10816317]

Lijowska AS, Reed NW, Chiodini BA, Thach BT. Sequential arousal and airway-defensive behavior of infants in asphyxial sleep environments. J Appl Physiol. 1997; 83:219-228. [PubMed: 9216967]

Lin Z, Chen ML, Keens TG, Ward SL, Khoo MC. Noninvasive assessment of cardiovascular autonomic control in congenital central hypoventilation syndrome. Conf Proc IEEE Eng Med Biol Soc. 2004; 5:3870-3873. [PubMed: 17271141]

Lipski J, Kanjhan R, Kruszewska B, Rong WF, Smith M. Pre-sympathetic neurones in the rostral ventrolateral medulla of the rat: electrophysiology, morphology and relationship to adjacent neuronal groups. Acta Neurobiol Exp (Wars). 1996; 56:373-384. [PubMed: 8787198]

Longin E, Gerstner T, Schaible T, Lenz T, König S. Maturation of the autonomic nervous system: differences in heart rate variability in premature vs. term infants. J Perinat Med. 2006; 34:303308. [PubMed: 16856820]

MacFarlane PM, Satriotomo I, Windelborn JA, Mitchell GS. NADPH oxidase activity is necessary for acute intermittent hypoxia-induced phrenic long-term facilitation. J Physiol. 2009; 587:19311942. [PubMed: 19237427]

Mahamed S, Mitchell GS. Is there a link between intermittent hypoxia-induced respiratory plasticity and obstructive sleep apnoea? Exp Physiol. 2007; 92:27-37. [PubMed: 17099064]

Makikallio TH, Huikuri HV, Hintze U, Videbaek J, Mitrani RD, Castellanos A, Myerburg RJ, Moller M. Fractal analysis and time- and frequency-domain measures of heart rate variability as predictors of mortality in patients with heart failure. Am J Cardiol. 2001; 87:178-182. [PubMed: 11152835]

Malloy MH, Freeman DH Jr. Birth weight- and gestational age-specific sudden infant death syndrome mortality: United States, 1991 versus 1995. Pediatrics. 2000; 105:1227-1231. [PubMed: 10835061]

Mandel DA, Schreihofer AM. Central respiratory modulation of barosensitive neurones in rat caudal ventrolateral medulla. J Physiol. 2006; 572:881-896. [PubMed: 16527859]

Martin RJ, DiFiore JM, Jana L, Davis RL, Miller MJ, Coles SK, Dick TE. Persistence of the biphasic ventilatory response to hypoxia in preterm infants. J Pediatr. 1998; 132:960-964. [PubMed: 9627586]

Masa JF, Corral J, Martin MJ, Riesco JA, Sojo A, Hernandez M, Douglas NJ. Assessment of thoracoabdominal bands to detect respiratory effort-related arousal. Eur Respir J. 2003; 22:661667. [PubMed: 14582921]

McAllen RM, Blessing WW. Neurons (presumably A1-cells) projecting from the caudal ventrolateral medulla to the region of the supraoptic nucleus respond to baroreceptor inputs in the rabbit. Neurosci Lett. 1987; 73:247-252. [PubMed: 3561866]

McCulloch K, Brouillette RT, Guzzetta AJ, Hunt CE. Arousal responses in near-miss sudden infant death syndrome and in normal infants. J Pediatr. 1982; 101:911-917. [PubMed: 7143167]

Mendelowitz D. Firing properties of identified parasympathetic cardiac neurons in nucleus ambiguus. Am J Physiol. 1996; 271:H2609-2614. [PubMed: 8997322]

Mendelowitz D, Kunze DL. Identification and dissociation of cardiovascular neurons from the medulla for patch clamp analysis. Neurosci Lett. 1991; 132:217-221. [PubMed: 1784423]

Meny RG, Carroll JL, Carbone MT, Kelly DH. Cardiorespiratory recordings from infants dying suddenly and unexpectedly at home. Pediatrics. 1994; 93:44-49. [PubMed: 8265322]

Mitchell EA, Williams SM, Taylor BJ. Use of duvets and the risk of sudden infant death syndrome. Arch Dis Child. 1999a; 81:117-119. [PubMed: 10490515]

Mitchell EA, Thach BT, Thompson JM, Williams S. Changing infants' sleep position increases risk of sudden infant death syndrome. New Zealand Cot Death Study. Arch Pediatr Adolesc Med. 1999b; 153:1136-1141. [PubMed: 10555714] 
Miyawaki T, Minson J, Arnolda L, Chalmers J, Llewellyn-Smith I, Pilowsky P. Role of excitatory amino acid receptors in cardiorespiratory coupling in ventrolateral medulla. Am J Physiol. 1996; 271:R1221-1230. [PubMed: 8945957]

Montgomery-Downs HE, Young ME, Ross MA, Polak MJ, Ritchie SK, Lynch SK. Sleep-disordered breathing symptoms frequency and growth among prematurely born infants. Sleep Med. 2010; 11:263-267. [PubMed: 20022298]

Moon RY. SIDS and other sleep-related infant deaths: expansion of recommendations for a safe infant sleeping environment. Pediatrics. 2011; 128:1030-1039. [PubMed: 22007004]

Moon RY, Horne RS, Hauck FR. Sudden infant death syndrome. Lancet. 2007; 370:1578-1587. [PubMed: 17980736]

Moore PJ, Ackland GL, Hanson MA. Unilateral cooling in the region of locus coeruleus blocks the fall in respiratory output during hypoxia in anaesthetized neonatal sheep. Exp Physiol. 1996; 81:983994. [PubMed: 8960704]

Moraes DJ, Zoccal DB, Machado BH. Sympathoexcitation during chemoreflex active expiration is mediated by L-glutamate in the RVLM/Botzinger complex of rats. J Neurophysiol. 2012; 108:610-623. [PubMed: 22539823]

Moriette G, Lescure S, El Ayoubi M, Lopez E. Apnea of prematurity: what's new? Arch Pediatr. 2010; 17:186-190. [PubMed: 19944573]

Morris JA. The common bacterial toxins hypothesis of sudden infant death syndrome. FEMS Immunol Med Microbiol. 1999; 25:11-17. [PubMed: 10443487]

Murry CE, Jennings RB, Reimer KA. Preconditioning with ischemia: a delay of lethal cell injury in ischemic myocardium. Circulation. 1986; 74:1124-1136. [PubMed: 3769170]

Neff RA, Simmens SJ, Evans C, Mendelowitz D. Prenatal nicotine exposure alters central cardiorespiratory responses to hypoxia in rats: implications for sudden infant death syndrome. J Neurosci. 2004; 24:9261-9268. [PubMed: 15496661]

Neff RA, Wang J, Baxi S, Evans C, Mendelowitz D. Respiratory sinus arrhythmia: endogenous activation of nicotinic receptors mediates respiratory modulation of brainstem cardioinhibitory parasympathetic neurons. Circ Res. 2003; 93:565-572. [PubMed: 12907666]

Nock ML, Difiore JM, Arko MK, Martin RJ. Relationship of the ventilatory response to hypoxia with neonatal apnea in preterm infants. J Pediatr. 2004; 144:291-295. [PubMed: 15001929]

Numao Y, Koshiya N, Gilbey MP, Spyer KM. Central respiratory drive-related activity in sympathetic nerves of the rat: the regional differences. Neurosci Lett. 1987; 81:279-284. [PubMed: 2893316]

Parslow PM, Harding R, Cranage SM, Adamson TM, Horne RS. Ventilatory responses preceding hypoxia-induced arousal in infants: effects of sleep-state. Respir Physiol Neurobiol. 2003; 136:235-247. [PubMed: 12853014]

Pena F, Ramirez JM. Endogenous activation of serotonin-2A receptors is required for respiratory rhythm generation in vitro. J Neurosci. 2002; 22:11055-11064. [PubMed: 12486201]

Pena F, Ramirez JM. Hypoxia-induced changes in neuronal network properties. Mol Neurobiol. 2005; 32:251-283. [PubMed: 16385141]

Pena F, Parkis MA, Tryba AK, Ramirez JM. Differential contribution of pacemaker properties to the generation of respiratory rhythms during normoxia and hypoxia. Neuron. 2004; 43:105-117. [PubMed: 15233921]

Peng CK, Havlin S, Stanley HE, Goldberger AL. Quantification of scaling exponents and crossover phenomena in nonstationary heartbeat time series. Chaos. 1995; 5:82-87. [PubMed: 11538314]

Petelczyc M, Zebrowski JJ, Baranowski R. Kramers-Moyal coefficients in the analysis and modeling of heart rate variability. Phys Rev E Stat Nonlin Soft Matter Phys. 2009; 80:031127. [PubMed: 19905082]

Pickering TG, Gribbin B, Petersen ES, Cunningham DJ, Sleight P. Effects of autonomic blockade on the baroreflex in man at rest and during exercise. Circ Res. 1972; 30:177-185. [PubMed: 4400823]

Pilowsky P. Good vibrations? Respiratory rhythms in the central control of blood pressure. Clin Exp Pharmacol Physiol. 1995; 22:594-604. [PubMed: 8542669]

Pincus SM. Approximate entropy as a measure of system complexity. Proc Natl Acad Sci U S A. 1991; 88:2297-2301. [PubMed: 11607165] 
Poets CF. Apparent life-threatening events and sudden infant death on a monitor. Paediatr Respir Rev. 2004; 5(Suppl A):S383-386. [PubMed: 14980301]

Ptak K, Yamanishi T, Aungst J, Milescu LS, Zhang R, Richerson GB, Smith JC. Raphe neurons stimulate respiratory circuit activity by multiple mechanisms via endogenously released serotonin and substance P. J Neurosci. 2009; 29:3720-3737. [PubMed: 19321769]

Ramanathan R, Corwin MJ, Hunt CE, Lister G, Tinsley LR, Baird T, Silvestri JM, Crowell DH, Hufford D, Martin RJ, Neuman MR, Weese-Mayer DE, Cupples LA, Peucker M, Willinger M, Keens TG. Cardiorespiratory events recorded on home monitors: Comparison of healthy infants with those at increased risk for SIDS. Jama. 2001; 285:2199-2207. [PubMed: 11325321]

Ramirez J, Quellmalz U, Richter D. Postnatal changes in the mammalian respiratory network as 626 revealed by the transverse brainstem slice of mice. J Physiol. 1996; 491:799-812. [PubMed: 8815212]

Ramirez JM, Quellmalz UJ, Wilken B. Developmental changes in the hypoxic response of the hypoglossus respiratory motor output in vitro. J Neurophysiol. 1997a; 78:383-392. [PubMed: 9242287]

Ramirez JM, Telgkamp P, Elsen FP, Quellmalz UJ, Richter DW. Respiratory rhythm generation in mammals: synaptic and membrane properties. Respir Physiol. 1997b; 110:71-85. [PubMed: 9407602]

Ramirez JM, Schwarzacher SW, Pierrefiche O, Olivera BM, Richter DW. Selective lesioning of the cat pre-Botzinger complex in vivo eliminates breathing but not gasping. J Physiol. 1998; 507 ( Pt 3):895-907. [PubMed: 9508848]

Reimer KA, Murry CE, Yamasawa I, Hill ML, Jennings RB. Four brief periods of myocardial ischemia cause no cumulative ATP loss or necrosis. Am J Physiol. 1986; 251:H1306-1315. [PubMed: 3789183]

Remmers JE, deGroot WJ, Sauerland EK, Anch AM. Pathogenesis of upper airway occlusion during sleep. J Appl Physiol. 1978; 44:931-938. [PubMed: 670014]

Rigatto H, Brady JP. Periodic breathing and apnea in preterm infants. I. Evidence for hypoventilation possibly due to central respiratory depression. Pediatrics. 1972; 50:202-218. [PubMed: 5045350]

Rigatto H, Brady JP, de la Torre Verduzco R. Chemoreceptor reflexes in preterm infants: I. The effect of gestational and postnatal age on the ventilatory response to inhalation of $100 \%$ and $15 \%$ oxygen. Pediatrics. 1975a; 55:604-613. [PubMed: 1128986]

Rigatto H, Brady JP, de la Torre Verduzco R. Chemoreceptor reflexes in preterm infants: II. The effect of gestational and postnatal age on the ventilatory response to inhaled carbon dioxide. Pediatrics. 1975b; 55:614-620. [PubMed: 1128987]

Roberts JL, Reed WR, Mathew OP, Thach BT. Control of respiratory activity of the genioglossus muscle in micrognathic infants. J Appl Physiol. 1986; 61:1523-1533. [PubMed: 3781966]

Rognum TO, Saugstad OD. Biochemical and immunological studies in SIDS victims. Clues to understanding the death mechanism. Acta Paediatr Suppl. 1993; 82(Suppl 389):82-85. [PubMed: 8374202]

Rosen CL, Larkin EK, Kirchner HL, Emancipator JL, Bivins SF, Surovec SA, Martin RJ, Redline S. Prevalence and risk factors for sleep-disordered breathing in 8- to 11-year-old children: association with race and prematurity. J Pediatr. 2003; 142:383-389. [PubMed: 12712055]

Sawaguchi T, Kato I, Franco P, Sottiaux M, Kadhim H, Shimizu S, Groswasser J, Togari H, Kobayashi M, Nishida H, Sawaguchi A, Kahn A. Apnea, glial apoptosis and neuronal plasticity in the arousal pathway of victims of SIDS. Forensic Sci Int. 2005; 149:205-217. [PubMed: 15749363]

Schmidt C, Bellingham MC, Richter DW. Adenosinergic modulation of respiratory neurones and hypoxic responses in the anaesthetized cat. J Physiol. 1995; 483 ( Pt 3):769-781. [PubMed: 7776257]

Schreiber T. Measuring information transfer. Phys Rev Lett. 2000; 85:461-464. [PubMed: 10991308]

Schuen JN, Bamford OS, Carroll JL. The cardiorespiratory response to anoxia: normal development and the effect of nicotine. Respir Physiol. 1997; 109:231-239. [PubMed: 9342800] 
Schwarzacher SW, Rub U, Deller T. Neuroanatomical characteristics of the human pre-Botzinger complex and its involvement in neurodegenerative brainstem diseases. Brain. 2011; 134:24-35. [PubMed: 21115469]

Sekul EA, Moak JP, Schultz RJ, Glaze DG, Dunn JK, Percy AK. Electrocardiographic findings in Rett syndrome: an explanation for sudden death? J Pediatr. 1994; 125:80-82. [PubMed: 8021793]

Selig FA, Tonolli ER, Silva EV, Godoy MF. Heart rate variability in preterm and term neonates. Arq Bras Cardiol. 2011; 96:443-449. [PubMed: 21584479]

Sharma PB, Baroody F, Gozal D, Lester LA. Obstructive sleep apnea in the formerly preterm infant: an overlooked diagnosis. Front Neurol. 2011; 2:73. [PubMed: 22144976]

Shykoff BE, Naqvi SS, Menon AS, Slutsky AS. Respiratory sinus arrhythmia in dogs. Effects of phasic afferents and chemostimulation. J Clin Invest. 1991; 87:1621-1627. [PubMed: 1902491]

Smith JC, Ellenberger HH, Ballanyi K, Richter DW, Feldman JL. Pre-Botzinger complex: a brainstem region that may generate respiratory rhythm in mammals. Science. 1991; 254:726-729. [PubMed: 1683005]

Slotkin TA, Saleh JL, McCook EC, Seidler FJ. Impaired cardiac function during postnatal hypoxia in rats exposed to nicotine prenatally: implications for perinatal morbidity and mortality, and for sudden infant death syndrome. Teratology. 1997; 55:177-184. [PubMed: 9181671]

Somers VK, Dyken ME, Mark AL, Abboud FM. Sympathetic-nerve activity during sleep in normal subjects. N Engl J Med. 1993; 328:303-307. [PubMed: 8419815]

Somers VK, White DP, Amin R, Abraham WT, Costa F, Culebras A, Daniels S, Floras JS, Hunt CE, Olson LJ, Pickering TG, Russell R, Woo M, Young T. Sleep apnea and cardiovascular disease: an American Heart Association/American College of Cardiology Foundation Scientific Statement from the American Heart Association Council for High Blood Pressure Research Professional Education Committee, Council on Clinical Cardiology, Stroke Council, and Council on Cardiovascular Nursing. J Am Coll Cardiol. 2008; 52:686-717. [PubMed: 18702977]

Sovik S, Lossius K, Eriksen M, Grogaard J, Walloe L. Development of oxygen sensitivity in infants of smoking and non-smoking mothers. Early Hum Dev. 1999; 56:217-232. [PubMed: 10636599]

Spyer KM, Gilbey MP. Cardiorespiratory interactions in heart-rate control. Ann N Y Acad Sci. 1988; 533:350-357. [PubMed: 3048175]

Stéphan-Blanchard E, Bach V, Telliez F, Chardon K. Perinatal nicotine/smoking exposure and carotid chemoreceptors during development. Respir Physiol Neurobiol. 2013; 185:110-119. [PubMed: 22743051]

Stornetta RL, Guyenet PG, McCarty RC. Autonomic nervous system control of heart rate during baroreceptor activation in conscious and anesthetized rats. J Auton Nerv Syst. 1987; 20:121-127. [PubMed: 3668159]

Stowe AM, Altay T, Freie AB, Gidday JM. Repetitive hypoxia extends endogenous neurovascular protection for stroke. Ann Neurol. 2011; 69:975-985. [PubMed: 21437933]

Tabar MRR, Ghasemi F, Peinke J, Friedrich R, Kaviani K, Taghavi F, Sadeghi S, Bizhani G, Sahimi M. New computational approaches to the analysis of interbeat intervals in human subjects. Computing in Science \& Engineering. 2006; 8:54-65.

Tan W, Janczewski WA, Yang P, Shao XM, Callaway EM, Feldman JL. Silencing preBotzinger complex somatostatin-expressing neurons induces persistent apnea in awake rat. Nat Neurosci. 2008; 11:538-540. [PubMed: 18391943]

Taylor EW, Butler PJ. Nervous control of heart rate: activity in the cardiac vagus of the dogfish. J Appl Physiol. 1982; 53:1330-1335. [PubMed: 7153133]

Telgkamp P, Ramirez JM. Differential responses of respiratory nuclei to anoxia in rhythmic brain stem slices of mice. J Neurophysiol. 1999; 82:2163-2170. [PubMed: 10561396]

Tfelt-Hansen J, Winkel BG, Grunnet M, Jespersen T. Cardiac channelopathies and sudden infant death syndrome. Cardiology. 2011; 119:21-33. [PubMed: 21778721]

Thach BT. Graded arousal responses in infants: advantages and disadvantages of a low threshold for arousal. Sleep Med. 2002; 3(Suppl 2):S37-40. [PubMed: 14592377]

Thach BT, Lijowska A. Arousals in infants. Sleep. 1996; 19:S271-273. [PubMed: 9085529] 
Thoby-Brisson M, Ramirez JM. Role of inspiratory pacemaker neurons in mediating the hypoxic response of the respiratory network in vitro. J Neurosci. 2000; 20:5858-5866. [PubMed: 10908629]

Trang H, Boureghda S, Denjoy I, Alia M, Kabaker M. 24-hour BP in children with congenital central hypoventilation syndrome. Chest. 2003; 124:1393-1399. [PubMed: 14555571]

Trelease RB, Harper RM, Sieck GC. Respiratory-related heart rate variation during sleep and waking states in cats. Exp Neurol. 1981; 72:195-203. [PubMed: 7202622]

Tryba AK, Pena F, Ramirez JM. Gasping activity in vitro: a rhythm dependent on 5-HT2A receptors. J Neurosci. 2006; 26:2623-2634. [PubMed: 16525041]

Tryba AK, Pena F, Lieske SP, Viemari JC, Thoby-Brisson M, Ramirez JM. Differential modulation of neural network and pacemaker activity underlying eupnea and sigh-breathing activities. $\mathrm{J}$ Neurophysiol. 2008; 99:2114-2125. [PubMed: 18287547]

Van de Borne P, Nguyen H, Biston P, Linkowski P, Degaute JP. Effects of wake and sleep stages on the 24-h autonomic control of blood pressure and heart rate in recumbent men. Am J Physiol. 1994; 266:H548-554. [PubMed: 8141356]

Vanoli E, De Ferrari GM, Stramba-Badiale M, Hull SS Jr, Foreman RD, Schwartz PJ. Vagal stimulation and prevention of sudden death in conscious dogs with a healed myocardial infarction. Circ Res. 1991; 68:1471-1481. [PubMed: 2019002]

Verbeek MM, Richardson HL, Parslow PM, Walker AM, Harding R, Horne RS. Arousal and ventilatory responses to mild hypoxia in sleeping preterm infants. J Sleep Res. 2008; 17:344353. [PubMed: 18503514]

Viemari JC, Ramirez JM. Norepinephrine differentially modulates different types of respiratory pacemaker and nonpacemaker neurons. J Neurophysiol. 2006; 95:2070-2082. [PubMed: 16394066]

Viemari JC, Garcia AJ 3rd, Doi A, Ramirez JM. Activation of alpha-2 noradrenergic receptors is critical for the generation of fictive eupnea and fictive gasping inspiratory activities in mammals in vitro. Eur J Neurosci. 2011; 33:2228-2237. [PubMed: 21615559]

Wang J, Irnaten M, Neff RA, Venkatesan P, Evans C, Loewy AD, Mettenleiter TC, Mendelowitz D. Synaptic and neurotransmitter activation of cardiac vagal neurons in the nucleus ambiguus. Ann N Y Acad Sci. 2001; 940:237-246. [PubMed: 11458681]

Wedgwood, RJ. Review of USA experience. In: Camps, FECRG., editor. Sudden and Unexpected Death in Infancy (Cot Deaths). Bristol, England: Wright; 1972.

Weese-Mayer DE, Kenny AS, Bennett HL, Ramirez JM, Leurgans SE. Familial dysautonomia: frequent, prolonged and severe hypoxemia during wakefulness and sleep. Pediatr Pulmonol. 2008a; 43:251-260. [PubMed: 18220270]

Weese-Mayer DE, Lieske SP, Boothby CM, Kenny AS, Bennett HL, Ramirez JM. Autonomic dysregulation in young girls with Rett Syndrome during nighttime in-home recordings. Pediatr Pulmonol. 2008b; 43:1045-1060. [PubMed: 18831533]

Weese-Mayer DE, Lieske SP, Boothby CM, Kenny AS, Bennett HL, Silvestri JM, Ramirez JM. Autonomic nervous system dysregulation: breathing and heart rate perturbation during wakefulness in young girls with Rett syndrome. Pediatr Res. 2006; 60:443-449. [PubMed: 16940240]

Wilken B, Ramirez JM, Probst I, Richter DW, Hanefeld F. Creatine protects the central respiratory network of mammals under anoxic conditions. Pediatr Res. 1998; 43:8-14. [PubMed: 9432106]

Willinger M, Hoffman HJ, Hartford RB. Infant sleep position and risk for sudden infant death syndrome: report of meeting held January 13 and 14, 1994, National Institutes of Health, Bethesda, MD. Pediatrics. 1994; 93:814-819. [PubMed: 8165085]

Wulbrand $\mathrm{H}, \mathrm{McNamara}$ F, Thach BT. The role of arousal related brainstem reflexes in causing recovery from upper airway occlusion in infants. Sleep. 2008; 31:833-840. [PubMed: 18548828]

Yeragani VK, Pohl R, Berger R, Balon R, Ramesh C, Glitz D, Srinivasan K, Weinberg P. Decreased heart rate variability in panic disorder patients: a study of power-spectral analysis of heart rate. Psychiatry Res. 1993; 46:89-103. [PubMed: 8464959] 
Yin X, Zheng Y, Liu Q, Cai J, Cai L. Cardiac response to chronic intermittent hypoxia with a transition from adaptation to maladaptation: the role of hydrogen peroxide. Oxid Med Cell Longev. 2012; 2012:569520. [PubMed: 22685619]

Yuan G, Adhikary G, McCormick AA, Holcroft JJ, Kumar GK, Prabhakar NR. Role of oxidative stress in intermittent hypoxia-induced immediate early gene activation in rat PC12 cells. J Physiol. 2004; 557:773-783. [PubMed: 15107478]

Zoccal DB, Simms AE, Bonagamba LG, Braga VA, Pickering AE, Paton JF, Machado BH. Increased sympathetic outflow in juvenile rats submitted to chronic intermittent hypoxia correlates with enhanced expiratory activity. J Physiol. 2008; 586:3253-3265. [PubMed: 18450774]

Zwicker JD, Rajani V, Hahn LB, Funk GD. Purinergic modulation of preBotzinger complex inspiratory rhythm in rodents: the interaction between ATP and adenosine. J Physiol. 2011; 589:4583-4600. [PubMed: 21788352]

Zwillich C, Devlin T, White D, Douglas N, Weil J, Martin R. Bradycardia during sleep apnea. Characteristics and mechanism. J Clin Invest. 1982; 69:1286-1292. [PubMed: 7085875] 


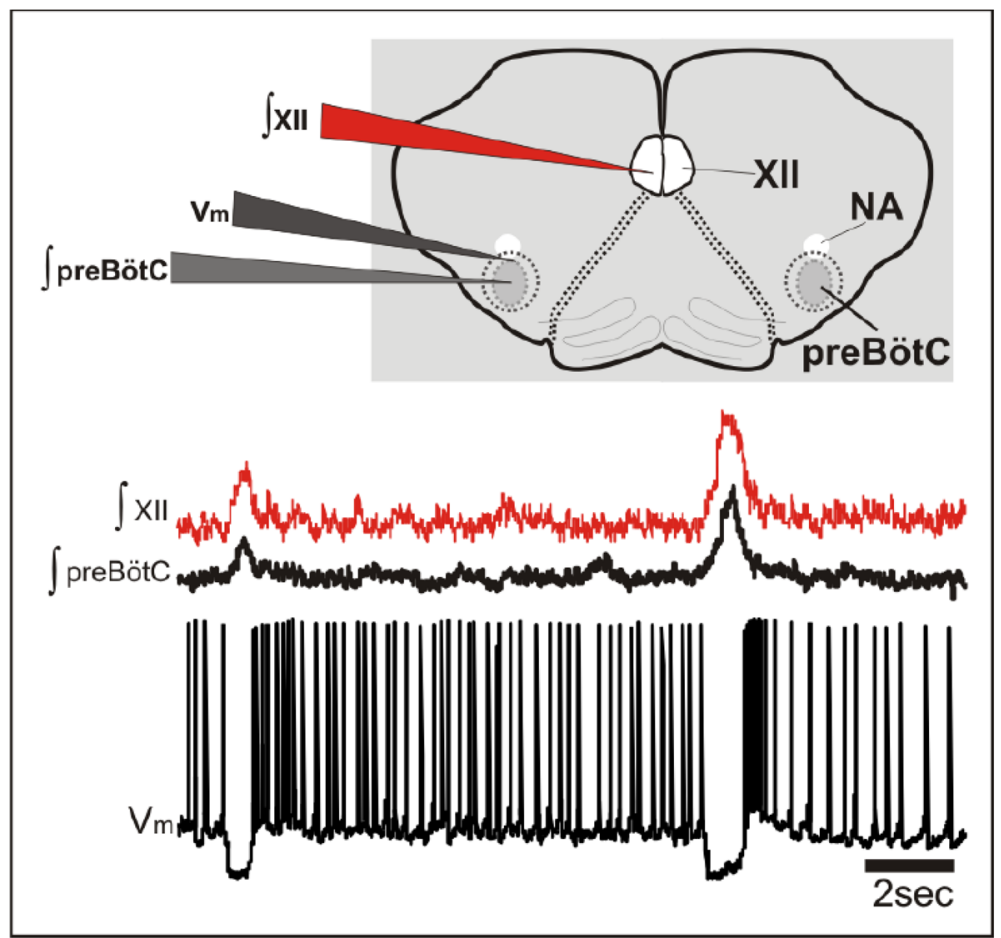

Figure 1. In vitro intracellular recording from a NA neuron within the rhythmic preBötC slice As shown in the membrane potential trace $\left(\mathrm{V}_{\mathrm{m}}\right)$, this putative NA neuron is phasically inhibited during inspiratory bursts from both the preBötC and hypoglossal nucleus (XII). This blind patch recording was made from a rhythmically active preBötC slice $(600 \mu \mathrm{m})$ prepared from a 7 day old mouse using procedures described in Ramirez et al. (1996) and approved by the Institutional Animal Care and Use Committee at Seattle Children's Research Institute. This neuron was identified as a choline acetyltransferase positive neuron located ventrally in the external formation of the NA. 

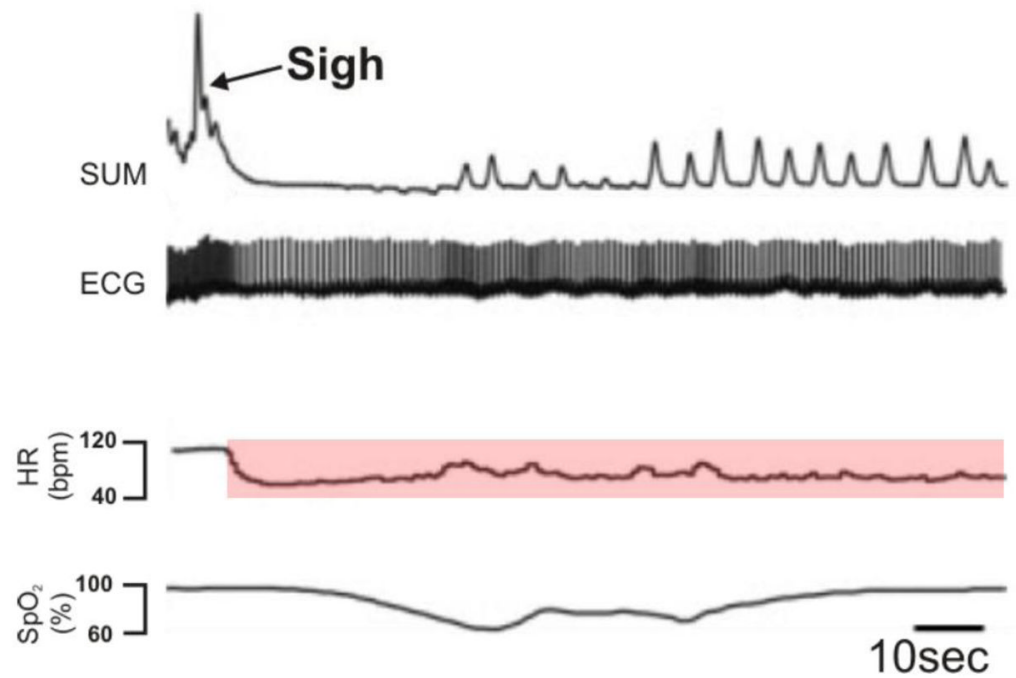

Figure 2. An example of the documented decrease in heart rate following a sigh in an individual with familial dysautonomia

SUM: Inductance plethysmography waveform noting the sigh; ECG: Electrocardiogram trace; HR: Heart rate, highlighted is the HR depression that is observed in familial dysautonomia; $\mathrm{SpO}_{2}$ : Hemoglobin saturation. (Weese-Mayer, 2008) 
A.

Normal

breathhold

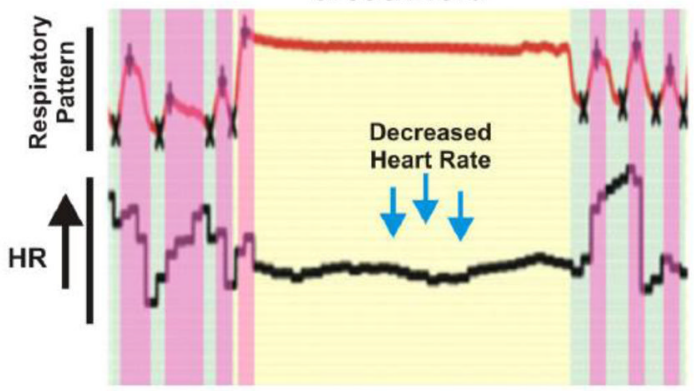

B.

Breathhold in Rett Syndrome

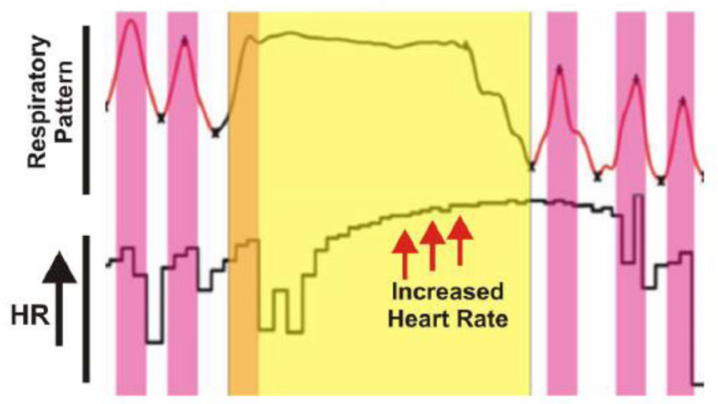

Figure 3. Breathhold and heart rate (HR) in a healthy individual and in a girl with Rett Syndrome

(A) During a breathhold in a healthy individual, HR decreases. (B) In Rett Syndrome, HR increases during breatholds. (Weese-Mayer, 2006) 
A

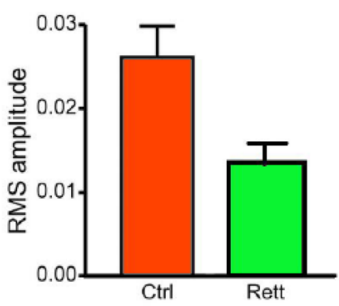

B

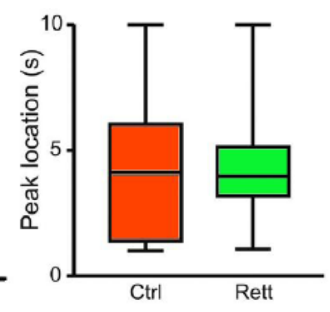

C

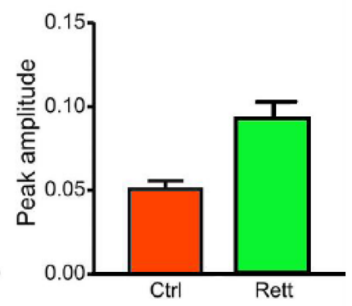

Figure 4. Cross-correlation analysis between respiration and heart frequencies Comparison of temporal characteristics characterizing cardiorespiratory couplings in a healthy individual (Ctrl) and an individual with Rett syndrome (Rett) shows in A) Root mean square of the amplitude of respiratory frequency components in controls and in Rett syndrome data. B) Time from the time-lag corresponding to the first maximum in the heart frequency component in response to respiration in control individuals and individuals with Rett syndrome. C) Amplitude of the first maximum in the heart frequency component during the breathholds in control individuals and individuals with Rett syndrome. (Weese-Mayer, 2006) 


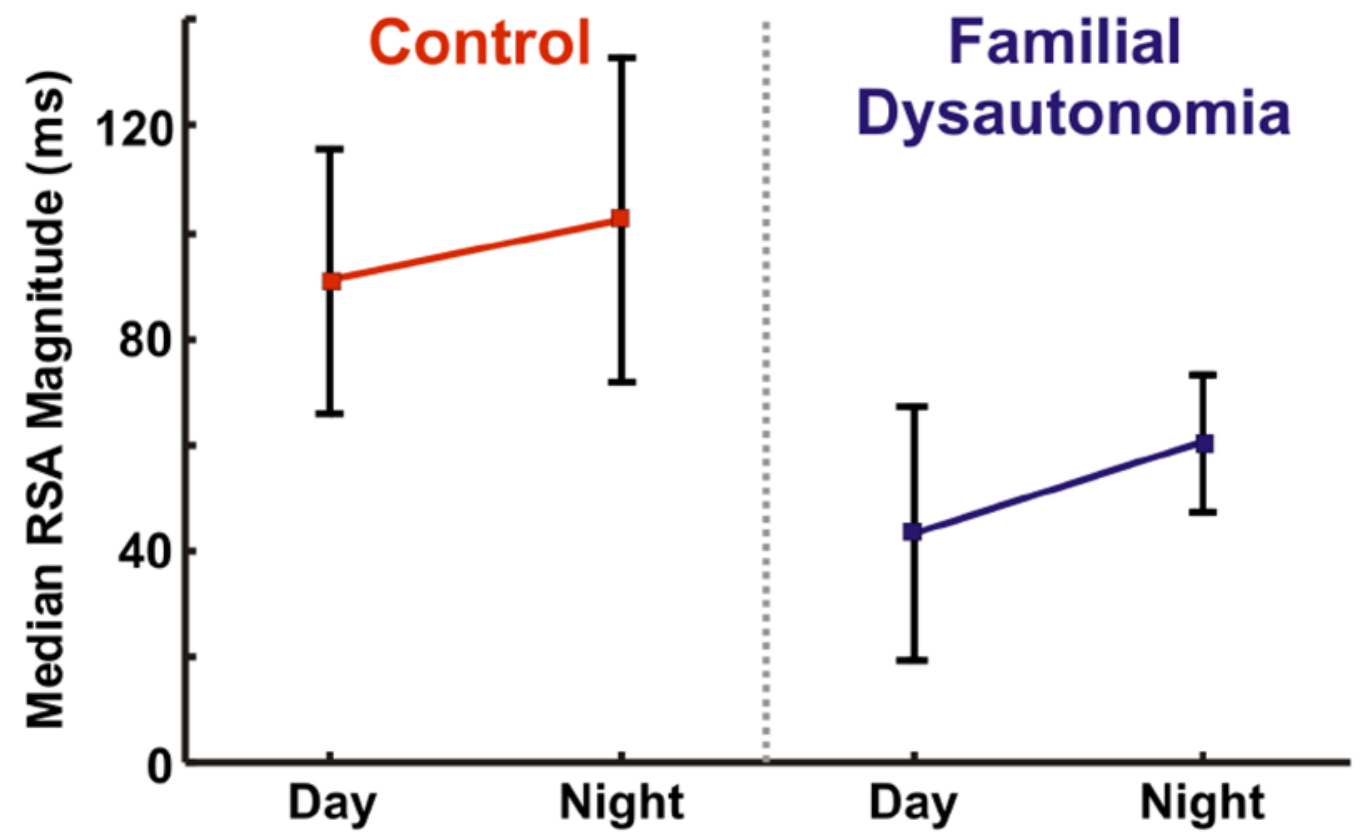

Figure 5. Mean RSA magnitude calculated from time-series dataset of healthy individuals (Control) and individuals with familial dysautonomia during daytime and nighttime Familial dysautonomia individuals: $\mathrm{RSA}_{\text {day }}=43.5 \pm 23.9 \mathrm{~ms}, \mathrm{RSA}_{\text {night }}=60.5 \pm 12.9 \mathrm{~ms}(\mathrm{P}-$ value $<0.001)$. Healthy individuals: $\mathrm{RSA}_{\text {day }}=91.0 \pm 24.8 \mathrm{~ms}, \mathrm{RSA}_{\text {night }}=102.5 \pm 30.4(\mathrm{P}-$ value $=0.0016)$ (Carroll et al., 2012). 